\title{
Expectations, Learning and Macroeconomic Persistence
}

\author{
FABIO MILANI \\ University of California, Irvine
}

\begin{abstract}
This paper presents an estimated model with learning and provides evidence that learning can improve the fit of popular monetary DSGE models and endogenously generate realistic levels of persistence.

The paper starts with an agnostic view, developing a model that nests learning and some of the structural sources of persistence, such as habit formation in consumption and inflation indexation, that are typically needed in monetary models with rational expectations to match the persistence of macroeconomic variables. I estimate the model by likelihood-based Bayesian methods, which allow the estimation of the learning gain coefficient jointly with the 'deep' parameters of the economy.

The empirical results show that when learning replaces rational expectations, the estimated degrees of habits and indexation drop near zero. This finding suggests that persistence arises in the model economy mainly from expectations and learning. The posterior model probabilities show that the specification with learning fits significantly better than does the specification with rational expectations.

Finally, if learning rather than mechanical sources of persistence provides a more appropriate representation of the economy, the implied optimal policy will be different. The policymaker will also incur substantial costs from misspecifying private expectations formation.
\end{abstract}

Keywords: persistence, constant-gain learning, expectations, habit formation in consumption, inflation inertia, Phillips curve, Bayesian econometrics, New-Keynesian model.

JEL classification: C11, D84, E30, E50, E52.

Date: First version: November 14, 2004. This version: August, 2005.

I am greatly indebted to Michael Woodford for his guidance and advice. I am grateful to Lars Svensson, Chris Sims, Klaus Adam, Francesco Belviso, Pierpaolo Benigno, Jean Boivin, Vasco Curdia, Jon Faust, Carlo Favero, Marc Giannoni, Michael Kiley, Athanasios Orphanides, Bruce Preston, Giorgio Primiceri, Ricardo Reis, John Roberts, Andrea Tambalotti, Noah Williams, Luis-Felipe Zanna, and all seminar participants at Columbia University, ECBUniversity of Frankfurt-Bundesbank, Federal Reserve Board, Federal Reserve of Cleveland Conference on "Empirical Methods and Applications for Dynamic Stochastic General Equilibrium Models and Factor Models" 2005, Federal Reserve of New York, North Carolina State University, Princeton University, SUNY Stony Brook, University of California at Irvine, University of Pennsylvania IUSC, and the 2005 World Congress of the Econometric Society, for comments and useful discussions. I would also like to thank Columbia University and the Federal Reserve Board for their hospitality during part of this project.

Address for correspondence: Department of Economics, 3151 Social Science Plaza, University of California, Irvine, CA 92697-5100. E-mail: fmilani@uci.edu. Homepage: http://www.socsci.uci.edu/ ${ }^{\text {fmilani. }}$ 


\section{INTRODUCTION}

Dynamic stochastic general equilibrium (DSGE) models have become a popular tool for the analysis of the monetary transmission mechanism. ${ }^{1}$ These models are built under the hypothesis of rational expectations and assume intertemporal optimizing behavior by economic agents. Being derived from explicit microeconomic foundations, they facilitate policy evaluation in terms of the welfare of private agents. Unfortunately, the canonical monetary models with rational expectations often cannot match the observed behavior of macroeconomic variables, and, in particular, they fail to match the persistence of aggregate output and inflation. Since a primary scope of these models is to serve for policy advice, a failure to reflect the dynamics of actual economic variables would necessarily limit their potential for that scope.

Economists have therefore proposed a number of extensions to the standard framework, by embedding in their setups potential sources of endogenous persistence. They have incorporated features such as habit formation in consumption, indexation to lagged inflation in price-setting, ruleof-thumb behavior, or various adjustment costs. Altig et al. (2004) and Christiano, Eichenbaum and Evans (2005) have developed models that incorporate several of these extensions and can account for the inertia in the data. Smets and Wouters (2003, 2004a) estimate similar models by Bayesian methods, incorporating a mix of frictions and persistent structural shocks, obtaining a remarkable fit of the data. Also, Boivin and Giannoni (2003) and Giannoni and Woodford (2003), working with smaller monetary policy models, but still incorporating a number of additional sources of persistence, derive impulse responses that approximate those derived from VARs. The cited extensions essentially improve the empirical fit by adding lags in the model equations. Researchers estimating these rich models under the assumption of rational expectations typically find that substantial degrees of habit persistence and inflation indexation are supported by the data. The exact value of the estimates varies, but there is consensus that these additional sources of persistence are necessary to match the inertia of macroeconomic variables.

Contribution of the paper. This paper suggests a different approach to the problem, by revisiting the standard expectations formation of the agents. The paper evaluates the potential for learning as a mechanism capable of endogenously generating persistence in the economy and improving the empirical fit of current monetary DSGE models. In particular, it studies whether

\footnotetext{
${ }^{1}$ Clarida, Gali', and Gertler (1999), Goodfriend and King (1997), McCallum and Nelson (1999), and Woodford (2003) are standard examples describing dynamic general equilibrium models for monetary policy analysis.
} 
learning or the 'mechanical' sources of persistence ${ }^{2}$ that are typically important under rational expectations, such as habits and indexation, are more successful in accounting for the observed behavior of macroeconomic variables. I therefore depart from the conventional rational expectations assumption, according to which agents have perfect knowledge about every detail in the economy. Agents in the model form expectations using correctly specified economic models (corresponding to the rational expectations solution), but they do not have knowledge about the parameters of the model. They use historical data to learn those parameters over time, updating their beliefs through constant-gain learning. The standard rational expectations specification is nested in the model as a limiting case. This is an appealing feature of the paper, since it allows, among other things, a simple test of the rational expectations hypothesis.

The paper therefore represents an attempt to study the empirical implications of learning. One possible way to proceed would consist of calibrating and simulating the model to evaluate if economic variables become more inertial under learning. The problem is that both learning and the mentioned endogenous sources of persistence may in principle lead to inertia. The different specifications can be close to observational equivalence (focusing, for example, on the implied first and second moments from the simulations), making difficult the test of one specification versus the other.

The present paper therefore starts from a more agnostic view. I develop a model in which agents are learning, but I also introduce some of the additional features that are essential to account for the persistence in the data under rational expectations. In particular, I allow for habit formation in consumption and indexation to past inflation in price-setting for non-optimizing firms. With such extensions, inflation and output may endogenously display inertia. The model therefore nests different sources of persistence: evolving expectations and learning on one side, and 'mechanical' sources of persistence on the other side. It is therefore left to the data to disentangle the role of the various sources. The scope will be to test whether those mechanical sources of persistence will still be necessary to match the data when the assumption of fully rational expectations is relaxed in favor of learning.

I estimate the model using likelihood-based Bayesian methods. The econometric approach allows me to jointly estimate the coefficients describing agents' learning, such as the gain coefficient

\footnotetext{
${ }^{2}$ I refer to them as 'mechanical' since in the case of habits, researchers need to alter the consumers' utility function to imply dependence on lagged consumption, and in the case of indexation, they posit a rule to induce inertia through the assumption that a fraction of firms simply adjust prices automatically, according to the past observed inflation rate.
} 
(indicating their learning speed), together with the 'deep' parameters of the economy. This strategy responds to a potential criticism of models with learning, in which the results might depend on the parameters that need to be chosen by the researcher. Here the learning speed is jointly estimated with the rest of the system, avoiding potential arbitrariness.

It is fundamental to identify the sources of persistence in the economy from a positive, but also from a normative, standpoint. Suppose that habit formation and inflation indexation are important features of the 'true' structure of the economy. In that case, habits and indexation would affect the welfare-based loss function that the policymaker should minimize, as shown in Woodford (2003). On the other hand, suppose that habits and indexation were added to the model mainly for empirical reasons, but turned out to be a mistaken representation of the economy (and were significant in the data only because they served as proxies for some omitted features): the welfare analysis under such microfoundations would then lead to misleading policy indications. With persistence driven by learning, the implied policy maker's loss function and constraints would in fact be different, and so would optimal policy. Also, in light of McCallum's (1988) argument for robustness of policy rules, even assuming rational expectations it would still be desirable to have an optimal policy that is at least robust to small deviations from full rationality. Optimal policy should instead take learning into account, if this is found to be empirically important.

In providing an empirical analysis of the importance of learning, the paper builds on previous literature on adaptive learning in macroeconomics. There are not many studies that empirically analyze the macroeconomic implications of adaptive learning. At the earlier stages, this literature was mainly theoretical and focused on the convergence of the system to the Rational Expectations Equilibrium (REE). Evans and Honkapohja (2003a,b), Bullard and Mitra (2002), and Preston (2003) are examples that verify the learnability of the REE in the context of monetary models. More recently, Bullard and Eusepi (2005), Cogley and Sargent (2005b), Orphanides and Williams (2003b), Primiceri (2003), Sargent (1999), and Sargent, Williams and Zha (2004), among others, have employed learning in empirical studies aimed at understanding the post-war evolution of US inflation and monetary policy. These papers share the use of learning as a tool that can help in understanding some particular historical episodes, often harder to explain in a rational expectations setup.

The present paper tries, instead, to provide a more general empirical study of the effects of learning. Its scope is akin to the work by Williams (2003) and Collard and Dellas (2004), who study the 
implications of learning for persistence and volatility in simple calibrated real and monetary business cycle models. Both papers investigate whether learning induces persistence and volatility by simulating their calibrated models and comparing the implied features of economic variables under learning and rational expectations. Collard and Dellas present a fully forward-looking monetary model where agents have imperfect information about some variables and gradually learn them over time. Their model performs better than the canonical complete information specification according to standard moments criteria. Williams finds, instead, little effects of learning in calibrated RBC or New Keynesian models, when agents learn about reduced forms of the aggregate laws of motion (finding more encouraging results when he allows agents to learn about structural features of the economy). Williams uses a specification of learning similar to this paper's, while Collard and Dellas' framework is more in the tradition of the imperfect information and signal extraction literature. The present paper shares their scope of studying the effects of learning, but differently from them it exploits actual data. This permits to verify if learning is supported by the empirical evidence and to compare the model with learning with alternative descriptions of the economy.

Similarly to recent empirical papers in macroeconomics, ${ }^{3}$ this paper adopts Bayesian methods in the estimation. Smets and Wouters $(2003,2004 \mathrm{a})$ provide first examples of estimated DSGE models, embedding several frictions and shocks, that fit the data as well as unrestricted VARs. Empirical studies typically work with DSGE models with rational expectations. The current paper instead uses Bayesian methods to estimate a DSGE model with non-fully rational expectations and learning. As anticipated, a potential criticism of models with adaptive learning, also discussed in Marcet and Nicolini (2003), emphasizes the arbitrary choices often available to the researcher, which render the model hardly falsifiable. Milani (2004), in fact, shows how his estimates strongly vary over the range of possible gain coefficients. In the present paper, instead, the gain coefficient is also estimated, leaving less room for arbitrariness. On the methodological side, the paper's joint estimation is similar in spirit to the approach of Sargent, Williams and Zha (2004), who employ a simple empirical model with learning and estimate some of the learning parameters (the variancecovariance matrix of the policymaker's initial beliefs, in their case) jointly with the other parameters of the economy.

More generally, by estimating a DSGE model with learning, the paper provides an example of a 'Non-Rational Expectations Econometrics' (or 'Irrational Expectations Econometrics'), which

\footnotetext{
${ }^{3}$ DeJong, Ingram and Whiteman (2000), Otrok (2001), Lubik and Schorfheide (2003, 2004), Smets and Wouters (2003, 2004, 2005), Rabanal and Rubio-Ramirez (2003), Fernandez-Villaverde and Rubio-Ramirez (2004a), Laforte (2003), Gali' and Rabanal (2004), and Justiniano and Preston (2004) are some examples.
} 
Ireland (2003) judged as missing from the branch of the literature that studies, usually theoretically, the impact of learning in macroeconomics.

Results. The empirical results show that the essential role of mechanical sources of persistence (habits, indexation) in DSGE monetary models rests on the assumption of fully rational expectations. When agents are allowed to learn the true parameters of the economy over time, I find that habits and indexation are no longer essential, being estimated at values close to zero in the data. This finding suggests that learning can represent an important source of persistence in the economy. Indeed, learning might represent a single mechanism capable of creating persistence, replacing the features needed in various sides of the conventional rational expectations model to improve its empirical properties. The posterior model probabilities show that the specification with learning (and no other sources of endogenous persistence) fits considerably better than the specification with rational expectations, even enriching the latter with habit formation and indexation. If learning rather than mechanical sources of persistence provides a more appropriate representation of the economy, the implied optimal policy will be different. Optimal policy under rational expectations performs poorly if implemented in a model where agents have instead imperfect knowledge and are learning, suggesting non-negligible welfare costs of misspecifying public expectations formation.

Outline. The paper is structured as follows. Section 2 presents the general framework, starting from the microfoundations of a standard DSGE model for monetary policy analysis and first considering the case of rational expectations. I allow for the existence of additional endogenous sources of persistence, such as indexation to past inflation and habit formation in private expenditure. Section 3 departs from rational expectations, introducing learning. It summarizes the aggregate dynamics of the model with learning and describes the expectations formation mechanism. The empirical part of the paper starts in Section 4, where I present the Bayesian techniques employed for estimation. Section 5 presents and discusses the empirical results. It also illustrates the results of a model comparison exercise between the learning and rational expectations models. Section 6 verifies the robustness of the findings to a number of extensions. The results have implications

for optimal policy, which are sketched in Section 7. Section 8 concludes and discusses possible directions for future research.

\section{The Framework}

In this section, I derive the aggregate dynamics for the economy, starting from the microeconomic foundations of a simple dynamic stochastic general equilibrium (DSGE) model (as in Woodford 
(2003)). Here, I present the model under the assumption of rational expectations. In the following of the paper, I shall depart from the conventional expectations formation mechanism, assuming that agents employ correctly specified models of the economy to form their expectations and learn the relevant parameters over time. The standard rational expectations specification will be nested in the model with learning as a special limiting case. I enrich the setup by introducing additional features that are usually needed under rational expectations to endow the model with minimally satisfactory empirical properties. A similar rational expectations framework has been used by Boivin and Giannoni (2003), Giannoni and Woodford (2003), and also described in Woodford (2003). First, I allow for habit persistence in the level of aggregate expenditure, assuming that the utility flow for each household $i$ in period $t$ depends not only on current expenditure $C_{t}^{i}$, but also on the level of expenditure in the previous period $C_{t-1}^{i}$. On the supply side, I allow for price indexation for firms that are not allowed to set their price optimally in a given period. This extension, recently proposed by Christiano, Eichenbaum and Evans (2005), generates more realistic levels of inflation inertia and has been also used in Smets and Wouters (2003, 2004a,b) and Altig et al. (2004).

2.1. Optimal Consumption with Habit Formation. I assume a standard economy populated by a continuum of households indexed by $i$ and distributed uniformly on the $[0,1]$ interval. Each household $i$ seeks to maximize a discounted sum of future utilities of the form:

$$
E_{t}\left\{\sum_{T=t}^{\infty} \beta^{T-t}\left[U\left(C_{T}^{i}-\eta C_{T-1}^{i} ; \zeta_{T}\right)-\int_{0}^{1} v\left(h_{T}^{i}(j) ; \zeta_{T}\right) d j\right]\right\}
$$

where $\beta \in(0,1)$ is the usual household's discount factor, $C_{T}^{i}$ is an index of the household's consumption of each of the differentiated goods supplied in $t, h_{T}^{i}(j)$ is the amount of labor supplied by household $i$ for the production of each good $j . \zeta_{T}$ is a vector of exogenous aggregate preference shocks. The parameter $0 \leq \eta \leq 1$ measures the degree of habit formation. Consumer's utility therefore depends positively on the deviation of consumption $C_{T}^{i}$ from an "internal" stock $\eta C_{T-1}^{i}$, and negatively on the total labor supplied. The function $U(\cdot ; \zeta)$ is increasing and concave for each $\zeta$ and $v(\cdot ; \zeta)$ is increasing and convex for each $\zeta$. I abstract from real money balances in the utility function, considering the cashless limiting economy described in Woodford (1998). $E_{t}$ represents the usual expectations operator and here denotes fully rational expectations. In the following of the paper, I will generalize it by assuming $\widehat{E}_{t}$, which instead indicates subjective (possibly non-rational) expectations. 
The consumption index is of the Dixit-Stiglitz CES form

$$
C_{t}^{i} \equiv\left[\int_{0}^{1} c_{t}^{i}(j)^{\frac{\theta-1}{\theta}} d j\right]^{\frac{\theta}{\theta-1}}
$$

and the associated aggregate price index is

$$
P_{t} \equiv\left[\int_{0}^{1} p_{t}(j)^{1-\theta} d j\right]^{\frac{1}{1-\theta}}
$$

where $\theta>1$ represents the elasticity of substitution between differentiated goods. Optimal consumption of good $j$ is given by $c_{t}^{i}(j)=C_{t}^{i}\left(p_{t}(j) / P_{t}\right)^{-\theta}$, where $p_{t}(j)$ is the price of good $j$ at date $t$. Financial markets are complete so that risks are efficiently shared and households face identical intertemporal budget constraints. ${ }^{4}$ I assume that the government has access to lump sum taxes and implements a Ricardian fiscal policy. I can therefore ignore the specific details of fiscal policy, since it does not influence aggregate economic variables in the model.

With habit formation, the first order conditions for the optimal choice of consumption imply

$$
\lambda_{t}=U_{c}\left(C_{T}-\eta C_{T-1} ; \zeta_{T}\right)-\beta \eta E_{t}\left[U_{c}\left(C_{T+1}-\eta C_{T} ; \zeta_{T+1}\right)\right]
$$

where the marginal utility of additional real income in period $t, \lambda_{t}$, is no longer simply equal to the marginal utility of consumption in that period. The marginal utility of income still satisfies

$$
\lambda_{t}=\beta E_{t}\left[\lambda_{t+1}\left(1+i_{t}\right) P_{t} / P_{t+1}\right]
$$

where $i_{t}$ denotes riskless one-period nominal interest rates. Substituting (2.4) in (2.5) and taking a log-linear approximation of the implied Euler equation, I derive:

$$
\widetilde{C}_{t}=E_{t} \widetilde{C}_{t+1}-(1-\beta \eta) \sigma\left(\widehat{i}_{t}-E_{t} \widehat{\pi}_{t+1}\right)+g_{t}-E_{t} g_{t+1}
$$

where

$$
\widetilde{C}_{t}=\widehat{C}_{t}-\eta \widehat{C}_{t-1}-\beta \eta E_{t}\left[\widehat{C}_{t+1}-\eta \widehat{C}_{t}\right]
$$

and where $\sigma \equiv \frac{-U_{c}}{\left(\bar{C} U_{c c}\right)}>0$ represents the elasticity of intertemporal substitution of consumption in the absence of habit formation, $g_{t} \equiv \frac{\sigma U_{c \zeta} \zeta_{t}}{U_{c}}$ represents exogenous preference shocks, and “^, on variables $C_{t}, i_{t}$ and $\pi_{t}$ denotes log-deviations of consumption, nominal interest rates, and inflation from their steady-state values. ${ }^{5}$ Boivin and Giannoni $(2003)$ refer to $[(1-\beta \eta) \sigma]$ as the 'pseudoelasticity of intertemporal substitution'. Using the equilibrium relationship $C_{t}=Y_{t}$, where $Y_{t}$

\footnotetext{
${ }^{4}$ I can therefore omit the superscript $i$ on $C_{t}^{i}$.

${ }^{5}$ I shall omit " , to indicate deviations from steady-state in the following of the paper, in order to save some notation.
} 
represents aggregate income in period $t$, and re-expressing in terms of the output gap $x_{t} \equiv Y_{t}-Y_{t}^{n}$ $\left(Y_{t}^{n}\right.$ is the natural rate of output, i.e. the equilibrium level of output under flexible prices) yields

$$
\widetilde{x}_{t}=E_{t} \widetilde{x}_{t+1}-(1-\beta \eta) \sigma\left[i_{t}-E_{t} \pi_{t+1}-r_{t}^{n}\right]
$$

where

$$
\widetilde{x}_{t} \equiv\left(x_{t}-\eta x_{t-1}\right)-\beta \eta E_{t}\left(x_{t+1}-\eta x_{t}\right)
$$

and $r_{T}^{n} \equiv[(1-\eta \beta) \sigma]^{-1}\left[\left(Y_{t+1}^{n}-g_{t+1}\right)-\left(Y_{t}^{n}-g_{t}\right)\right]$ is the flexible-price equilibrium real interest rate (the real interest rate in an equilibrium where $x_{t}=0$ at all times).

2.2. Optimal Price Setting. I assume a continuum of monopolistically competitive firms. Following Calvo (1983), a fraction $0<1-\alpha<1$ of firms are allowed to change their price in a given period. ${ }^{6}$ The price of the remaining fraction $\alpha$ is adjusted according to the indexation rule (proposed by Christiano, Eichenbaum and Evans 2005)

$$
\log p_{t}(i)=\log p_{t-1}(i)+\gamma \pi_{t-1}
$$

where firms that cannot set their price optimally in a given period simply index to lagged inflation. Inflation indexation has been also employed in Smets and Wouters (2003, 2004a,b), Altig et al. (2004), and Giannoni and Woodford (2003), and such assumption enables them to improve the empirical performance of their models. The parameter $0 \leq \gamma \leq 1$ represents the degree of indexation to past inflation. Christiano, Eichenbaum and Evans (2005) assumed $\gamma=1$, meaning full indexation.

Firm $i$ is a monopolistic supplier of good $i$, which is produced according to the production technology $y_{t}(i)=A_{t} f\left(h_{t}(i)\right)$, where $A_{t}$ is an exogenous technology shock, $h_{t}(i)$ is labor input and the function $f(\cdot)$ is increasing and concave. Capital is assumed to be fixed, leaving labor as the only variable factor of production. Firms face a common demand curve $y_{t}(i)=Y_{t}\left(\frac{p_{t}(i)}{P_{t}}\right)^{-\theta}$ for their product, where $Y_{t}=\left[\int_{0}^{1} y_{t}(i)^{\frac{(\theta-1)}{\theta}} d i\right]^{\frac{\theta}{\theta-1}}$ is the aggregate output and $P_{t}$ the aggregate price index, both taken as given. All firms face the same decision problem and, if they are allowed to change their price, they set the common price $p_{t}^{*}$. It follows that the aggregate price index evolves according to

$$
P_{t}=\left[\alpha\left(P_{t-1}\left(\frac{P_{t-1}}{P_{t-2}}\right)^{\gamma}\right)^{1-\theta}+(1-\alpha) p_{t}^{* 1-\theta}\right]^{\frac{1}{1-\theta}}
$$

\footnotetext{
${ }^{6}$ Although unrealistic, the assumption of Calvo price-setting is common in models of monetary policy analysis since it permits to solve the model without tracking the distribution of prices across firms.
} 
Firms set $p_{t}^{*}$ to maximize the expected present discounted value of future profits:

$$
E_{t}\left\{\sum_{T=t}^{\infty} \alpha^{T-t} Q_{t, T}\left[\Pi_{T}\left(p_{t}^{*}(i)\left(\frac{P_{T-1}}{P_{t-1}}\right)^{\gamma}\right)\right]\right\}
$$

where $Q_{t, T}=\beta^{T-t} \frac{P_{t}}{P_{T}} \frac{\lambda_{T}}{\lambda_{t}}$ is the stochastic discount factor, and $\Pi_{T}(\cdot)$ denotes period $T$ firm's nominal profits given by

$$
\Pi_{T}(p)=p_{t}^{*}(i)\left(\frac{P_{T-1}}{P_{t-1}}\right)^{\gamma} Y_{T}\left(\frac{p_{t}^{*}(i)\left(\frac{P_{T-1}}{P_{t-1}}\right)^{\gamma}}{P_{T}}\right)^{-\theta}-w_{t}(i) f^{-1}\left(\frac{Y_{T}}{A_{T}}\left(\frac{p_{t}^{*}(i)\left(\frac{P_{T-1}}{P_{t-1}}\right)^{\gamma}}{P_{T}}\right)^{-\theta}\right)
$$

where $w_{t}(i)$ represents the wage for labor supplied in the production of good $i$. Firms discount future profits at rate $\alpha$, since they can expect the optimal price chosen at date $t$ to apply in period $T$ with probability $\alpha^{T-t}$, and at the discount factor $Q_{t, T}$. The firm chooses $\left\{p_{t}^{*}(i)\right\}$ to maximize the flux of profits (2.12), for given $\left\{Y_{T}, P_{T}, w_{T}(j), A_{T}, Q_{t, T}\right\}$ for $T \geq t$ and $j \in[0,1]$.

Log-linearization of the first-order condition ${ }^{7}$ for this problem yields

$$
\widehat{p}_{t}^{*}(i)=E_{t} \sum_{T=t}^{\infty}(\alpha \beta)^{T-t}\left[\frac{1-\alpha \beta}{1+\omega \theta}\left(\omega \widehat{Y}_{T}-\widehat{\lambda}_{T}+\frac{v_{y \zeta}}{v_{y}} \zeta_{T}\right)+\alpha \beta\left(\widehat{\pi}_{T+1}-\gamma \widehat{\pi}_{T}\right)\right]
$$

where $\widehat{p}_{t}^{*} \equiv \log \left(p_{t}^{*} / P_{t}\right)$ and $\omega \equiv v_{y y} \bar{Y} / v_{y}$ is the elasticity of the marginal disutility of producing output with respect to an increase in output.

From a log-linear approximation of the aggregate price index $(2.11)$, notice that $\widehat{p}_{t}^{*}=\frac{\alpha}{(1-\alpha)}\left(\widehat{\pi}_{t}-\gamma \widehat{\pi}_{t-1}\right)$, which plugged in the previous expression gives the following law of motion for inflation

$$
\tilde{\pi}_{t}=\xi_{p}\left[\omega x_{t}+[(1-\eta \beta) \sigma]^{-1} \widetilde{x}_{t}\right]+\beta E_{t} \tilde{\pi}_{t+1}+u_{t}
$$

where

$$
\begin{gathered}
\tilde{\pi}_{t} \equiv \pi_{t}-\gamma \pi_{t-1} \\
\widetilde{x}_{t} \equiv\left(x_{t}-\eta x_{t-1}\right)-\beta \eta E\left(x_{t+1}-\eta x_{t}\right) \\
\xi_{p}=\frac{(1-\alpha)(1-\alpha \beta)}{\alpha(1+\omega \theta)}
\end{gathered}
$$

and where $u_{t} \equiv \frac{v_{y \zeta}}{v_{y} \xi_{p}} \zeta_{t}$ represents an exogenous aggregate supply shock. As seen, $x_{t}$ represents the theoretical output gap, i.e. the deviation of actual output from the natural rate of output that would prevail under flexible prices. None of the commonly employed measures of the output gap are

\footnotetext{
${ }^{7}$ Consistently with most of the New Keynesian literature, I log-linearize around a zero steady-state for inflation. I am therefore abstracting from the complications arising from log-linearizing around a positive inflation steady-state. For an account of the possible implications of this choice, see Kiley (2004) and Ascari (2004). Indexation permits to avoid the problems due to trend inflation, as shown in the appendix A of Ascari (2004). The present paper, however, works with partial indexation, remaining partly vulnerable to such problems.
} 
totally appropriate as empirical proxies of the deviations of output from that theoretical concept. In the empirical part of the paper I will use the Congressional Budget Office (CBO)'s estimate of potential output. ${ }^{8}$ Notice that any deviation of the empirical output gap from the theoretical output gap will materialize in the supply shock $u_{t}$.

\section{A Simple Model with Learning and Structural Sources of Persistence}

3.1. Aggregate Dynamics. In this section, I follow a number of papers in the adaptive learning literature, ${ }^{9}$ starting from the derived linearized equations under rational expectations (eq. (2.8) and (2.15)) and replacing the assumption of fully rational expectations with subjective expectations. ${ }^{10}$ The aggregate dynamics for output and inflation is given by the following specification, nesting learning and mechanical sources of persistence

$$
\begin{aligned}
& \widetilde{x}_{t}=\widehat{E}_{t} \widetilde{x}_{t+1}-(1-\beta \eta) \sigma\left[i_{t}-\widehat{E}_{t} \pi_{t+1}-r_{t}^{n}\right] \\
& \widetilde{\pi}_{t}=\xi_{p}\left[\omega x_{t}+[(1-\eta \beta) \sigma]^{-1} \widetilde{x}_{t}\right]+\beta \widehat{E}_{t} \widetilde{\pi}_{t+1}+u_{t}
\end{aligned}
$$

where

$$
\begin{gathered}
\tilde{\pi}_{t} \equiv \pi_{t}-\gamma \pi_{t-1} \\
\widetilde{x}_{t} \equiv\left(x_{t}-\eta x_{t-1}\right)-\beta \eta \widehat{E}\left(x_{t+1}-\eta x_{t}\right) .
\end{gathered}
$$

Here $\widehat{E}_{t}$ indicates subjective (possibly non-rational) expectations. As under rational expectations, current output gap depends on lagged and expected one-period and two-period ahead output gaps, and on the ex-ante real interest rate. Consistently with Boivin and Giannoni (2003), Giannoni and Woodford (2003), and Woodford (2003), it is more appropriate here to interpret $\eta$ broadly as the degree of habit formation in private expenditure, rather than simply in non-durable consumption. Under this interpretation, habits would also capture the persistence in investment, serving as a proxy for adjustment costs. Current inflation depends on lagged and one-period ahead

\footnotetext{
${ }^{8}$ Alternatives in the literature consist of employing detrended output, through Hodrick-Prescott filter or removing some linear or quadratic trend, as measures of the output gap. Another possibility would consist of finding the real-time potential output through filtering techniques.

${ }^{9}$ Evans and Honkapohja (2001, 2003a,b), Bullard and Mitra (2002), Bullard and Eusepi (2005), and Williams (2003) are some examples.

${ }^{10}$ For a different approach of considering learning, see Preston (2003), where learning is introduced directly from the primitive assumptions of multi-period decision problems. I shall also introduce learning as in Preston (2003) later in the paper, illustrating the model and the implied empirical results. For a full derivation of the model with learning from microfoundations, also incorporating habits in consumption and price indexation, see Appendix A.
} 
inflation, and on current, lagged and one-period-ahead output gap. With habit formation, the log marginal utility of real income entering the Phillips curve is written, in fact, as a linear function of $\widetilde{x}_{t}$ rather than as a linear function of $x_{t}$ (which was the case for $\left.\eta=0\right) .{ }^{11}$ Notice that I could have derived similar equations for output and inflation dynamics, only with different restrictions on the parameters, assuming the existence of rule-of-thumb behavior (Gali' and Gertler 1999, Amato and Laubach 2003), instead of habits and indexation. The results in the following of the paper are not dependent on this choice. The presented framework nests the cases of rational expectations, where $\widehat{E}_{t}=E_{t}$ (I will explain this case later in more details), no habits (for $\eta=0$ ), and no indexation (for $\gamma=0$ ).

I introduce monetary policy in the model and assume that it can be described by the following Taylor rule with partial adjustment

$$
i_{t}=\rho i_{t-1}+(1-\rho)\left[\psi_{\pi} \pi_{t}+\psi_{x} x_{t}\right]+\varepsilon_{t}
$$

where $\rho$ denotes the degree of interest-rate smoothing, $\psi_{\pi}$ and $\psi_{x}$ are the feedback coefficients to inflation and output gap, and the monetary policy shock $\varepsilon_{t}$ accounts for unanticipated deviations from the systematic monetary policy rule. A similar rule implies that monetary policy has been constant over the sample. The stability of monetary policy over the pre-79 and post-82 periods is still controversial. An influential paper by Clarida, Gali' and Gertler (2000) shows that monetary policy has been passive and destabilizing in the U.S. before 1979, active and stabilizing after 1982 (along these lines are also Boivin and Giannoni 2003, Cogley and Sargent 2005a, and Lubik and Schorfheide 2004). Other papers, such as Sims (2001) and Sims and Zha (2004) find instead no evidence of shifts in the systematic part of monetary policy. ${ }^{12}$ Assuming that monetary policy can be expressed as a simple constant Taylor rule is probably overly simplistic. But for the purpose of estimation of the model with learning it may represent a first useful approximation. A simple rule is also used in recent papers estimating rational expectations DSGE models, such as Smets and Wouters $(2003,2004 \mathrm{a}) .{ }^{13}$ In the following of the paper, however, I will also allow for a time-varying monetary policy rule as a robustness check. An alternative would consist of introducing optimal monetary policy. Under learning, however, it is important to specify the degree of knowledge the

\footnotetext{
${ }^{11}$ When $\eta=0$, the aggregate dynamics of inflation (with indexation) would be given by $\widetilde{\pi}_{t}=\xi_{p}\left(\omega+\sigma^{-1}\right) x_{t}+$ $\beta \widehat{E}_{t} \widetilde{\pi}_{t+1}+u_{t}$, which is the case considered in Milani (2004).

${ }^{12}$ In Sims and Zha (2004), the best fitting model is one with no changes in the coefficients and only changes in the variances of the structural disturbances.

${ }^{13}$ They introduce a time-varying target for inflation in the policy rule. I will also estimate a rule of this kind in the next sections.
} 
central bank has about private sector expectations. The central bank might be assumed to have perfect knowledge about the agents' learning rules or might instead formulate optimal policy under the mistaken perception that agents have rational expectations. The resulting optimal policy would be different depending on the various assumptions. In this paper, I abstract from these possibilities and instead use a rule that has been shown to fit well in previous empirical work.

I assume that the natural real interest rate and the cost-push shocks evolve according to univariate $\mathrm{AR}(1)$ processes

$$
\begin{aligned}
& r_{t}^{n}=\phi^{r} r_{t-1}^{n}+\nu_{t}^{r} \\
& u_{t}=\phi^{u} u_{t-1}+\nu_{t}^{u}
\end{aligned}
$$

where $\nu_{t}^{r} \sim \operatorname{iid}\left(0, \sigma_{r}^{2}\right), \nu_{t}^{u} \sim \operatorname{iid}\left(0, \sigma_{u}^{2}\right)$

3.2. Expectations Formation: Constant-Gain Learning. As made clear by eq. (3.1) and (3.2), agents need to form forecasts of future macroeconomic conditions. Following recent learning literature, I assume that agents behave as econometricians, employing an economic model and forming expectations from that model.

Agents estimate

$$
Z_{t}=a_{t}+b_{t} Z_{t-1}+c_{t} u_{t}+d_{t} r_{t}^{n}+\varepsilon_{t}
$$

using variables that appear in the Minimum State Variable (MSV) solution of the system under rational expectations (defining $Z_{t} \equiv\left[\pi_{t}, x_{t}, i_{t}\right]^{\prime}$ and where $a_{t}, b_{t}, c_{t}, d_{t}$ are coefficient vectors and matrices of appropriate dimensions). ${ }^{14}$ Therefore, the agents employ a correct model of the economy, but they do not have knowledge about the relevant model parameters (as they would have under rational expectations). ${ }^{15}$ They use historical data to learn those parameters over time. Expression (3.8) represents the "Perceived Law of Motion" or PLM of the agents. As additional data become available in subsequent periods, agents update their estimates of the coefficients $\left(a_{t}, b_{t}, c_{t}, d_{t}\right)$ according to the constant-gain learning (CGL) formula

$$
\begin{aligned}
\widehat{\phi}_{t} & =\widehat{\phi}_{t-1}+\overline{\mathbf{g}} R_{t-1}^{-1} X_{t}\left(Z_{t}-X_{t}^{\prime} \widehat{\boldsymbol{\phi}}_{t-1}\right) \\
R_{t} & =R_{t-1}+\overline{\mathbf{g}}\left(X_{t-1} X_{t-1}^{\prime}-R_{t-1}\right)
\end{aligned}
$$

\footnotetext{
${ }^{14}$ See McCallum (1999) for a presentation of the MSV criterion to choose the "fundamental" solution of linear RE systems.

${ }^{15}$ In the estimation, I will assume that agents recognize that the true mean of the variables is zero $\left(a_{t}=0\right)$. Allowing agents to learn also the constant term over time has no effects on the results.
} 
where $\widehat{\phi}_{t}$ describes the updating of the learning rule coefficients, $\widehat{\phi}_{t}=\left(a_{t}^{\prime}, \operatorname{vec}\left(b_{t}, c_{t}, d_{t}\right)^{\prime}\right)^{\prime}$, and $R_{t}$ denotes the matrix of second moments of the stacked regressors $X_{t} \equiv\left\{1, Z_{t-1}, u_{t}, r_{t}^{n}\right\}_{0}^{t-1}$. The constant gain is expressed by the parameter $\overline{\mathbf{g}}$ and, compared with the recursive least squares (RLS) gain (equal to $1 / t$ ), represents a simple way to model learning of an agent concerned about potential structural breaks at unknown dates. ${ }^{16}$ CGL in fact gives more weight to more recent observations (it is a variant of what is more generally called bounded-memory learning and, for clarity, it mimics the situation of an econometrician running rolling-window regressions). Differently from RLS learning the economy will not converge to the Rational Expectations Equilibrium (REE), but it might only converge to an ergodic distribution around it. A larger value of the gain coefficient $\mathbf{g}$ would imply faster learning of potential shifts, but would also lead to higher volatility around the steady state.

The assumption that agents form expectations using only variables that appear in the MSV solution is not entirely realistic. This assumption facilitates comparison with the previous theoretical literature that commonly employs it. An alternative would be to allow agents to estimate simple unrestricted VARs and form expectations from those.

Using their PLM and the updated parameter estimates, agents form expectations for any horizon $T>t$ as

$$
\begin{aligned}
\widehat{E}_{t} Z_{T}= & \left(I_{5}-b_{t-1}\right)^{-1}\left(I_{5}-b_{t-1}^{T-t}\right) a_{t-1}+b_{t-1}^{T-t} E_{t} Z_{t}+ \\
& \phi_{u} u_{t}\left(\phi_{u} I_{5}-b_{t-1}\right)^{-1}\left(\phi_{u}^{T-t} I_{5}-b_{t-1}^{T-t}\right) c_{t-1}+\phi_{r} r_{t}^{n}\left(\phi_{r} I_{5}-b_{t-1}\right)^{-1}\left(\phi_{r}^{T-t} I_{5}-b_{t-1}^{T-t}\right) d_{t-1}
\end{aligned}
$$

where $I_{5}$ denotes a $5 \times 5$ identity matrix. The model information assumptions are as follows: in period $t$, agents observe the values of the endogenous variables in $t-1$, they observe the values of the shocks in $t$, and they use the estimated parameters in $t-1$ (which they have derived from a regression of endogenous variables in $t-1$ on the endogenous variables in $t-2$ and observed shocks in $t-1)$, to form expectations for future periods $t+1$ and $t+2 .{ }^{17}$

In each period $t$, agents use an econometric model to form their expectations about future variables, but they do not take into account their subsequent updating in periods $T>t$. Therefore,

\footnotetext{
${ }^{16}$ Constant-gain learning has been used in various recent empirical studies, such as Orphanides and Williams (2003a,b, 2004, 2005), Williams (2003), and Primiceri (2003), among others. Orphanides and Williams also refer to it as perpetual learning.

${ }^{17}$ The information assumptions are similar to Evans and Honkapohja (2003a,b) and Preston (2003).
} 
they act as adaptive decision-makers, in accordance with what Kreps (1998) defines as an anticipated utility model. ${ }^{18}$ This is a standard assumption in the adaptive learning literature and it is discussed in more length in Cogley and Sargent (2004). ${ }^{19}$ An appealing characteristics of the learning framework presented here is that it nests rational expectations as a special limiting case, i.e. the case for $\overline{\mathbf{g}} \rightarrow 0$. It would be therefore interesting to examine whether a strictly positive gain leads to improvements in explaining the data. Also the framework nests several possible learning cases characterized by the parameter $\overline{\mathbf{g}}$, according to which agents are more or less willing to update their expectations based on new information.

Furthermore, as discussed by Orphanides and Williams (2003b), modeling agents' learning permits to accommodate the Lucas critique, since agents' expectations endogenously adjust to changes in policy. This is not entirely true for structural models in the case that all the dynamics come from the frictions needed to insert lags in the model equations.

Branch and Evans (2005) show that constant-gain learning models fit the forecasts from surveys better than alternative methods for both inflation and output growth. In particular, constant-gain learning models dominate models with optimal constant gain (obtained by minimizing the forecasts' Mean Square Error), with Kalman Filter, and with Recursive Least Squares learning. Their results therefore provide supportive evidence of constant-gain learning as a model of actual expectations formation.

To summarize, the model economy is represented by the aggregate dynamics equations (3.1), (3.2), monetary policy rule (3.5), shock processes (3.6), (3.7), and expectations formation expressions (3.9), (3.10) and (3.11).

3.3. State-Space Form. Substituting the expectations formed as in (3.11) into (3.1) and (3.2) yields the state-space form

$$
\begin{aligned}
\xi_{t} & =A_{t}+F_{t} \xi_{t-1}+G_{t} w_{t} \\
Y_{t} & =H \xi_{t}
\end{aligned}
$$

\footnotetext{
${ }^{18}$ According to an anticipated utility model, each period agents maximize their expected utility taking their beliefs and the model as constant, although the model is recursively estimated. When more data become available, agents update their beliefs and use this new knowledge to maximize expected utility. Agents are therefore learning, but they are not involved in active experimentation as a fully rational behavior would imply.

${ }^{19}$ As Cogley and Sargent (2004) discuss, a full Bayesian procedure in many macroeconomic models would be too complicated to be implemented. Anticipated utility models can be therefore thought as a useful approximation to more complex decision problems. They also show that the anticipated utility model provides an excellent approximation of the Bayesian solution in simple examples (and it is more successful than a rational expectations approximation).
} 
where $\xi_{t}=\left[x_{t}, \pi_{t}, i_{t}, u_{t}, r_{t}^{n}\right], w_{t} \sim N(0, Q), H$ is a matrix of zeros and ones just selecting variables from $\xi_{t},{ }^{20}$ and $A_{t}, F_{t}, G_{t}$ are time-varying matrices of coefficients, which are convolutions of structural parameters of the economy and agents beliefs. Expression (3.12) is the implied "Actual Law of Motion", or ALM, of the economy (and it is different from, although depending on, the agents' PLM). I shall estimate the system by Bayesian methods. The scope will be to test whether persistence is due to structural characteristics, such as habits and indexation, or instead to learning behavior by firms and consumers.

\section{BAyEsian Estimation}

I estimate the system using likelihood-based Bayesian methods to fit the series for output gap, inflation and the nominal interest rate. A number of recent papers in empirical macroeconomics have employed Bayesian methods to estimate DSGE models of the economy. DeJong, Ingram, and Whiteman (2000) illustrated Bayesian estimation of Real Business Cycles models using importance sampling, while Otrok (2001) applied the Metropolis-Hastings algorithm. Schorfheide (2005), Lubik and Schorfheide (2003, 2004), Smets and Wouters (2003, 2004, 2005), Rabanal and Rubio-Ramirez (2003), Laforte (2003), Gali' and Rabanal (2004), and Justiniano and Preston (2004) are all recent examples of papers exploiting Bayesian methods to estimate DSGE models. Smets and Wouters (2003), in particular, provide a first example of an estimated structural model that succeeds to fit as well as an a-theoretic Bayesian VAR. ${ }^{21}$ This paper follows a similar approach in estimation. While the cited papers work with traditional rational expectations models, I provide an example of estimation of a simple DSGE model with non-fully rational expectations and learning. A simple empirical model with learning is presented and estimated in Sargent, Williams and Zha (2004). ${ }^{22}$

As shown in Fernandez-Villaverde and Rubio-Ramirez (2004a), Bayesian methods also have an appealing classical interpretation: Bayesian point estimates converge asymptotically to their pseudo-true values and the best model according to the Kullback-Leibler measure will be also the

\footnotetext{
${ }^{20}$ Because of the well-known stochastic singularity of standard RE systems, where there are more endogenous variables than shocks ( 5 vs. 3 here), I follow the common approach of computing the likelihood only on a subset of the variables $\left(x_{t}, \pi_{t}, i_{t}\right.$ in this case).

${ }^{21}$ All these papers work with linearized models. Fernandez-Villaverde and Rubio-Ramirez (2004b) show how to estimate the nonlinear representation of a DSGE model. The computational burden however dramatically increases and it is likely to become unbearable, for the moment, in a model that also contains learning.

${ }^{22}$ They estimate a model where the monetary authority updates its beliefs about the Phillips curve and show that the rise and fall of post-war US inflation can be attributed to the interaction between policymaker's beliefs and realized economic shocks.
} 
model obtaining highest posterior probability in Bayesian model comparison. ${ }^{23}$ In their empirical exercise, they also show that Bayesian estimates outperform Maximum Likelihood estimates in small samples.

Using the model in state-space form in (3.12), I estimate the deep parameters and the main learning parameter, the constant gain, jointly in the system. I can evaluate the likelihood function using the Kalman Filter. To derive the parameter estimates, I generate draws from the posterior distribution using the Metropolis algorithm.

The structural parameters of the model are collected in the parameter vector $\theta$ :

$$
\theta=\left\{\eta, \beta, \sigma, \gamma, \xi_{p}, \omega, \rho, \chi_{\pi}, \chi_{x}, \phi_{r}, \phi_{u}, \sigma_{\varepsilon}, \sigma_{r}, \sigma_{u}, \overline{\mathbf{g}}\right\}
$$

where $\sigma_{\varepsilon}, \sigma_{r}, \sigma_{u}$ are the standard deviations of the shocks to monetary policy, aggregate demand, and aggregate supply.

The parameter vector $\theta$ therefore includes the structural parameters describing the dynamics of the economy, the policy rule coefficients, the standard deviations of the shocks, and the constant gain coefficient $\mathbf{g}$. In particular, the estimate of the constant gain coefficient is crucial, since despite its increasing use in monetary policy studies, estimates of its value are missing in the literature. Ireland (2003) highlights the necessity of what he defines an "irrational expectations econometrics" and suggests estimating the gain using time series data, also to assess whether a deviation from the rational expectations value $(\overline{\mathbf{g}} \rightarrow 0)$ helps improving the model's fit. This is exactly what is done in the paper. The value to assign to $\overline{\mathbf{g}}$ constitutes an important degree of freedom for the researcher and one's results may heavily depend on its choice. Indeed, Milani (2004) shows how the estimated degree of structural persistence in inflation strongly depends on the assumed speed of learning by the private sector. Similarly, Orphanides and Williams (2004), using a smaller range of possible gain values, illustrate how persistence and volatility vary with the gain. They show that both persistence and volatility increase with larger gain coefficients (being at their lowest values under rational expectations). This paper hence provides an estimate of $\overline{\mathbf{g}}$ to fill the gap in the literature. ${ }^{24}$ Notice that the structural parameters and the learning speed are jointly estimated in the system. This is different from the estimation performed in Milani (2004), where the estimation

\footnotetext{
${ }^{23}$ This is attractive, since from decision theory the Kullback-Leibler measure represents the criterion that an agent should rationally use to choose between competing models (see Fernandez-Villaverde and Rubio-Ramirez 2004a and references therein).

${ }^{24}$ Orphanides and Williams (2003b, 2005) estimate the constant-gain coefficient as the gain the minimizes the deviation of expectations in their model from the Survey of Professional Forecasters' expectations series.
} 
of structural parameters was valid for a given estimated learning rule (that paper used a two-step estimation procedure). ${ }^{25}$

All the information about the parameters is summarized by the posterior distribution, obtained by Bayes Theorem

$$
p\left(\theta \mid Y^{T}\right)=\frac{p\left(Y^{T} \mid \theta\right) p(\theta)}{p\left(Y^{T}\right)}
$$

where $p\left(Y^{T} \mid \theta\right)$ is the likelihood function, $p(\theta)$ the prior for the parameters, and $Y^{T}=\left[y_{1}, \ldots, y_{T}\right]^{\prime}$ collects the data histories.

The model is fitted to data on output gap, inflation, and nominal interest rates. The data are quarterly for the period 1960:I to 2004:II. Inflation is defined as the annualized quarterly rate of change of the GDP Implicit Price Deflator, output gap as the log difference between GDP and Potential GDP (CBO estimate), ${ }^{26}$ and I use the federal funds rate as the nominal interest rate. The series were obtained from FRED, the database of the Federal Reserve Bank of Saint Louis. I run 300, 000 draws for the Markov Chain, discarding the first 20\% as initial burn-in.

4.1. Specifying the Prior Distribution. First, I need to specify a prior distribution over the structural parameters collected in $\theta$. Table 1 presents information about the priors.

\section{Insert Table 1 about here}

Priors are assumed to be independent. The habit and indexation parameters $\eta$ and $\gamma$ are assumed to follow Uniform distributions in the interval $[0,1]$. I have also experimented Beta and Normal prior distributions for those parameters. The discount factor $\beta$ follows a Beta distributions, but with a really tight probability around 0.99. I assume Uniform distributions for all the autoregressive parameters $\left(\rho, \phi_{r}, \phi_{u}\right)$ that should assume values in the interval $[0,1)$. The intertemporal elasticity of substitution coefficient $\sigma$ follows a Gamma distribution with mean 0.125 and standard deviation 0.09. I choose Normal distributions for the other structural parameters and inverse gamma distributions for the standard deviations of the shocks. The prior for $\omega$ is centered at the value estimated by Giannoni and Woodford (2003), with a rather large variance. For the constant-gain coefficient, I assume a Gamma distribution that guarantees it assumes values only in $\mathbb{R}^{+}$: the gain

\footnotetext{
${ }^{25}$ Ideally, one would want to estimate also the initial values and the initial variance-covariance matrix of agents' beliefs jointly in the system. Here, however, I avoid this complication to keep the number of estimated parameters tractable. I start by fixing the initial beliefs and the initial variances. Later in the paper, I will also use estimated initial beliefs, calculated from pre-sample data.

${ }^{26}$ As discussed in the previous section, deviations of the empirical output gap from the theoretically relevant gap will appear in the supply shock $u_{t}$.
} 
has prior mean 0.031 and prior standard deviation 0.022. Since I do not have strong prior beliefs for this coefficient, lacking estimates in previous literature, I shall also check, later in the paper, the results under a more diffuse prior distribution, assuming for example a Uniform distribution in the interval $[0,0.3]$.

4.2. Metropolis-Hastings Algorithm. To generate draws from the posterior distribution of $\theta$ using the Metropolis-Hastings algorithm, I need to evaluate the likelihood function $p\left(Y^{T} \mid \theta\right)$ at each iteration. Having expressed the model as a linear Gaussian system in (3.12), I can easily compute the likelihood recursively with the Kalman Filter. The details of the procedure are illustrated in the appendix.

I obtain a Markov Chain $\left\{\theta_{1}, \theta_{2}, \ldots, \theta_{D}\right\}$ of parameter values, where $D$ represents the total number of draws ( $D=300,000$ in the paper). Given this Markov Chain and a function of interest $g(\cdot)$, it is possible to prove that $\widehat{\mu}=\frac{1}{D} \sum_{j=1}^{D} g\left(\theta_{j}\right)$ converges almost surely to $\mu=E[g(\theta)]$ as $D \rightarrow \infty$.

Application of a Central Limit Theorem implies $\sqrt{D}(\widehat{\mu}-\mu) \stackrel{D}{\longrightarrow} N\left(0, \sigma_{\mu}^{2}\right)$. To compute the numerical standard errors $\sigma_{\mu}$ of the parameter estimates, however, I need to take into account the autocorrelation of the draws (since the Markov Chain does not produce iid draws). I use the method suggested by Geweke (1999) of estimating the standard error as $\left(\frac{1}{D} \widehat{S_{g}}(0)\right)^{\frac{1}{2}}$, where $\widehat{S_{g}}(0)$ represents the spectral density of function $g(\cdot)$ evaluated at the origin. ${ }^{27}$

\section{Some (Non-)Rational Expectations Econometrics: Empirical Results}

5.1. Model with Learning. I present the results of the estimation of the model with learning in Table 2 .

\section{Insert Table 2 about here}

The degree of habit formation in private expenditures, measured by the parameter $\eta$, equals 0.117. The estimated degree of inflation indexation $\gamma$ equals 0.03 . The reported $95 \%$ asymmetric posterior probability intervals indicate that the estimates are unlikely to be higher than 0.3 for habits and 0.1 for indexation. Habits and indexation are typically essential features in rational expectations models to match the persistence in the data and to improve fit. When learning replaces the assumption of fully rational expectations, the importance of habits and indexation drops to values close to zero. Mechanical sources of endogenous persistence appear no longer essential for

\footnotetext{
${ }^{27}$ Due to the high number of draws in the estimation of the learning and rational expectations models, the numerical standard errors, indicating the accuracy of the Monte Carlo approximation, are all found in the range 0.02 or lower.
} 
the empirical performance of DSGE models. The result suggests that learning is able to generate the necessary persistence in the economy, leaving no role for those additional features.

The other parameters are estimated at realistic values. The intertemporal elasticity of substitution ( $\sigma$ in the absence of habits) equals 0.748 . The monetary policy rule shows a sizeable degree of interest-rate smoothing ( $\rho=0.914$ ), a feedback coefficient to inflation equal 1.484 and to the output gap equal 0.801. From the estimate of $\xi_{p}$, I can calculate the implied degree of price stickiness, i.e. the Calvo parameter $\alpha$. The implied $\alpha$ equals $0.709,{ }^{28}$ which indicates that firms re-optimize their prices every 3.44 quarters.

A central coefficient in my estimation is represented by the constant gain. This paper represents the first attempt to estimate the gain jointly with the rest of the parameters of the economy. The posterior mean estimate for the gain equals 0.0183. Such a value implies that private agents are learning rather slowly. The estimated value is not too dissimilar from values chosen from calibration in previous studies (often working with gains in the interval $0.015-0.03$ ) and from what found by Orphanides and Williams (2003b, 2004), exploiting data on expectations from the Survey of Professional Forecasters. ${ }^{29}$ To facilitate intuition, the gain can be interpreted as an indication of how many past observations agents use to form their expectations. A gain of 0.0183 indicates that agents make use of roughly 13 - 14 years of data (54. 6 quarters). Also, looking at expressions (3.9) and (3.10), it can be noticed that with a gain of that size only a small fraction of new information is used to update the previous period coefficients' estimates.

Figure 1 shows the evolution of agents' beliefs over the sample.

\section{Insert Figure 1 about here}

Coefficient $b_{22}$ in the graph represents the evolution of agents' beliefs about the persistence of inflation (the autoregressive parameter in their learning rule). Agents start with a low perceived persistence of inflation during the 1960s, but they revise their beliefs at the end of the 1970s and at the beginning of the 1980s. The perceived persistence drops later in the 1980s, increasing again in the second half of the 1990s. A similar dynamics, but with substantially larger autoregressive coefficients, is found in Milani (2004) in a related paper about inflation inertia, and in Orphanides and Williams (2003b). Coefficient $b_{21}$ instead indicates the estimated sensitivity of inflation to the output gap. The figure shows that in the 1970s the sensitivity was high, but it decreased in the

\footnotetext{
${ }^{28}$ The value is computed using the estimated parameters and assuming $\theta=7.69$.

${ }^{29}$ They found values of $\mathbf{g}$ in the range $0.01-0.04$ to perform better and they adopted $\overline{\mathbf{g}}=0.02$ in their baseline model.
} 
latest two decades. This result is consistent with the perception of a flatter Phillips curve in such period. The figure also reports the estimated $95 \%$ posterior probability interval of the evolving beliefs. They show that the beliefs are tightly estimated (with uncertainty usually increasing in the second half of the sample).

Figure 2 instead reports the evolution of agents' forecasts of inflation compared with the realized inflation series.

\section{Insert Figure 2 about here}

From the figure, prolonged periods of correlated errors in the forecasts of inflation are apparent. Private agents underestimated inflation in the 1970s and, in particular, they were not successful in predicting the first peak in 1974-75. They rapidly increased their inflation forecasts in the second part of the 1970s, maintaining them higher than realized inflation during the first quarters of Volcker's disinflation. The agents again repeatedly overestimated inflation in the second part of the 1990s, when inflation remained low despite the booming economy. The dynamics of inflation expectations is consistent with actual expectations from surveys, in which private agents have typically underestimated inflation when it was high and overestimated it when it was low. Explaining long periods of persistent forecast errors is instead harder under rational expectations.

Turning to the methodological aspects of the estimation, notice that I have not restricted the analysis to parameter spaces leading to convergence around the REE. An interesting extension in the estimation would be to consider regions of the parameter space characterized by E-stability (learnability of the REE) and E-instability, possibly extending to models with learning the approach of Lubik and Schorfheide (2004), who showed how to deal with determinacy and indeterminacy spaces in rational expectations models. This extension is beyond the scope of this paper though.

5.2. Model with Rational Expectations. In this section, I re-estimate the model under the assumption of rational expectations. The model now consists of equations (2.8), (2.15), hence with

$E_{t}$ replacing $\widehat{E}_{t}$, together with (3.5), (3.6) and (3.7), and is similar to the system estimated by Giannoni and Woodford (2003) and Boivin and Giannoni (2003), for example. In their empirical exercise, they use an indirect estimation method, choosing parameters to minimize the distance between the model's implied impulse response functions and those obtained from a VAR. Working with a closely related model, I compare my results to theirs. To avoid the discrepancies driven by the different methods used in estimation rather than the assumed method of expectations formation, I re-estimate the system with the same Bayesian procedure previously implemented for the learning 
case. This permits a more accurate comparison between the resulting estimates and allows me to evaluate the relative models' fit.

The log-linearized model under rational expectations can be written (following Sims (2002)) as

$$
\Gamma_{0} \xi_{t}=\Gamma_{1} \xi_{t-1}+\Psi w_{t}+\Pi \eta_{t}
$$

where I have introduced the vector of expectational errors $\eta_{t}=z_{t}-E_{t-1} z_{t}$ for any variable $z_{t}$.

The model expressed as (5.1) has solution

$$
\xi_{t}=F \xi_{t-1}+G w_{t}+\Theta_{\xi} \sum_{j=1}^{\infty} \Theta_{f}^{j-1} \Theta_{w} E_{t}\left[w_{t+j}\right]
$$

where the last term drops out if $w_{t}$ is i.i.d. (as in this paper).

From expression (5.2), ${ }^{30}$ and again adding the observation equation $Y_{t}=H \xi_{t}$, I can estimate the system by computing the likelihood through the Kalman Filter and using the Metropolis-Hastings algorithm to draw from the posterior distribution. In the estimation, I abstract from the complications arising from estimating the model under both the determinacy and indeterminacy regions as in Lubik and Schorfheide (2004). Here, consistently with the rest of the empirical literature estimating DSGE models, I impose the restriction that the parameters lay within the determinacy region. If the data were, instead, best described by parameters laying in the indeterminacy space, the restrictions would lead to biased estimates. Only a small percentage of the draws $(0.0187 \%)$, however, fell in the indeterminacy region and were discarded.

The estimation results are reported in Table 3, together with the estimates found by Giannoni and Woodford (2003).

\section{Insert Table 3 about here}

I estimate sizeable degrees of indexation in inflation $(\gamma=0.885)$ and habit formation in consumption $(\eta=0.911)$. Notice, however, that the autoregressive parameter in the cost-push shock is now much lower $\left(\phi_{u}=0.02\right)$ than it was under learning. This likely explains a lot of the increase in the estimated indexation. In the next section, I will present another estimation of a learning model (with infinite-horizon learning) in which the degree of indexation falls, and it is coupled with a low estimated autocorrelation of the cost-push shock. A large degree of habit formation and a large autocorrelation of the exogenous shock are instead necessary in the output gap equation.

The estimates are not too far from those found by Giannoni and Woodford (2003). ${ }^{31}$ The biggest difference with their estimates is given by the pseudo-elasticity of intertemporal substitution

\footnotetext{
${ }^{30}$ Under RE, the matrices $F$ and $G$ are no longer time-varying.

${ }^{31}$ The samples do not coincide. They use a post-1982 sample in their estimation, while I use data from 1960 to 2004. The results reported correspond to the specification with habits, indexation, and flexible wages, in their paper.
} 
parameter (denoted by $\varphi^{-1}=[(1-\beta \eta) \sigma]$ ), which also measures the sensitivity of output to changes in the real interest rate. My estimate implies a lower sensitivity. The difference probably arises here from the different estimation methods: the impulse responses from a VAR show a substantial response of the gap to a monetary shock. Their estimated parameter needs to match this response and is therefore bigger $\left(\varphi^{-1}=1.50\right)$. Standard estimates of this parameter by other methods are typically considerably lower (and mine equals $\varphi^{-1}=0.26$ ).

Again, from the estimated $\xi_{p}$ I can derive the implied price stickiness coefficient $\alpha$. I obtain $\alpha=0.922$, which implies that firms keep their prices fixed for more than 3 years. This degree of price rigidity is unrealistic, but it often appears in estimated models. Therefore, when learning replaces rational expectations also the implied price rigidity decreases toward values that are more consistent with the microeconometric evidence.

The estimation results reaffirm what is commonly known: in rational expectations DSGE models, additional sources of endogenous persistence are essential to match the inertial behavior of economic variables and make the model fit.

\subsubsection{Do We Really Need Mechanical Sources of Persistence? As shown in Table 3, Giannoni} and Woodford (2003), working with the same model of this paper but with rational expectations instead of learning, estimate both $\eta=1$ and $\gamma=1$, suggesting extremely high degrees of structural persistence. Boivin and Giannoni (2003) also find $\eta \simeq 1$ and $\gamma=1$. Christiano, Eichenbaum, and Evans (2004) and Altig, Christiano, Eichenbaum, and Linde' (2005) do not actually estimate $\gamma$, but they fix it to 1, indicating full indexation; they estimate instead $\eta$, both obtaining a value of 0.65 . Smets and Wouters (2004) estimate on US data $\eta=0.69$ and $\gamma=0.66$ in their pre-79 sample, and $\eta=0.44$ and $\gamma=0.34$ in the post- 82 sample. Their estimates are somewhat lower than other papers, but still surprisingly large if we consider that they are obtained in a rich model, incorporating, besides habits, sticky prices, and indexation, also wage stickiness, capital formation, adjustment costs, and several highly autocorrelated shocks. ${ }^{32}$ Dennis (2003) estimates a new-Keynesian model with optimal monetary policy and finds $\eta \simeq 1$ and $\gamma \simeq 0.9$. A macroeconomic study about the importance of habit formation in consumption (using time series on consumption rather than output) is instead Fuhrer (2000b), who also obtains a strong role for habits $(\eta=0.8-0.9) .{ }^{33}$ Rabanal

\footnotetext{
${ }^{32}$ The variables they use are also different: they use a measure of inflation that is detrended by a linear trend, for example.

${ }^{33}$ The evidence of habit formation in consumption in microeconomic data is instead weaker. Dynan (2000), looking at households' data from the PSID, find no evidence of habits.
} 
and Rubio-Ramirez (2003) instead compare different sticky-price models, estimating $\gamma=0.76$. All those results point towards extremely high levels of structural persistence in the economy and are common in current empirical studies. ${ }^{34}$ As discussed in the introduction, mechanical sources of persistence are essential to make rational expectations models fit.

This paper has shown that estimated degrees of habit formation and inflation indexation close to 1 seem to hinge on the assumption of fully rational expectations. When this assumption is weakened by allowing agents to learn over time, the degree of persistence due to structural features of the economy (habits and indexation here but possibly others) drops to almost zero. This result highlights the role of expectations and learning dynamics as sufficient sources of persistence in the economy. $^{35}$

5.3. Model Comparison: Learning vs. Rational Expectations. In this section, I compare the posterior model probabilities of the specifications with learning and rational expectations. To derive the posterior probabilities, I need to compute the models' marginal likelihoods. The ratio of the probabilities between two competing models is called Bayes Factor. This Bayesian concept is related to the classical Likelihood Ratio (LR). But as Fernandez-Villaverde and Rubio-Ramirez (2004a) discuss, the Bayes Factor has some advantages over the likelihood ratio: there is no need of an arbitrary choice of a significance level and it avoids the problem of the LR test, which can simultaneously accept or reject different nulls due to the asymmetry in the treatment of the different hypothesis.

The posterior odds between the constant-gain learning (CGL) and rational expectations (RE) models are computed as

$$
\frac{p_{C G L, T}}{p_{R E, T}}=\left(\frac{p_{C G L, 0}}{p_{R E, 0}}\right)\left(\frac{p\left(Y^{T} \mid \mathcal{M}_{C G L}\right)}{p\left(Y^{T} \mid \mathcal{M}_{R E}\right)}\right)
$$

where the first term on the right-hand-side is the prior odds ratio and the second the Bayes Factor. ${ }^{36}$

\footnotetext{
${ }^{34}$ It is worth mentioning that some of the cited papers use different specifications of habits, therefore their estimated reduced form equation for output is different.

${ }^{35}$ In a very different context, Gordon and Leeper (2003) are also able to derive persistence from expectations (agents' expectations of future fiscal policies in their case), suggesting that careful modeling of expectations as a source of sluggishness in the economy might deserve further attention.

${ }^{36}$ Following the suggestion in Jeffreys (1961), the interpretations of the posterior odds are: $\frac{p_{C G L, T}}{p_{R E, T}}<1$ the null of RE is supported; $1<\frac{p_{C G L, T}}{p_{R E, T}}<3.16$ some evidence against the null; $3.16<\frac{p_{C G L, T}}{p_{R E, T}}<10$ substantial evidence against the null; $10<\frac{p_{C G L, T}}{p_{R E, T}}<33.3$ strong evidence against the null; $33.3<\frac{p_{C G L, T}}{p_{R E, T}}<100$ very strong evidence against the null; $\frac{p_{C G L, T}}{p_{R E, T}}>100$ decisive evidence against the null.
} 
The posterior probabilities of each model instead derive from a simple application of Bayes' Theorem and are given by

$$
p_{i, T}=\frac{p\left(Y^{T} \mid \mathcal{M}_{i}\right) p_{i, 0}}{\sum_{\mathcal{M}} p\left(Y^{T} \mid \mathcal{M}_{i}\right) p_{i, 0}}
$$

where $i=C G L, R E$ and $\mathcal{M}$ represents the space of all possible models. The marginal data densities $p\left(Y^{T} \mid \mathcal{M}_{i}\right)$ are defined as

$$
p\left(Y^{T} \mid \mathcal{M}_{i}\right)=\int L\left(\theta_{j} \mid Y^{T}, \mathcal{M}_{i}\right) p\left(\theta_{j} \mid \mathcal{M}_{i}\right) d \theta_{j}
$$

I compute the marginal likelihood using Geweke's (1999) Modified Harmonic Mean approximation. $^{37}$

I present the results in Table 4 and 5.

\section{Insert Table 4 and 5 about here}

Table 4 shows the model comparison between the models with learning and rational expectations, both allowing for habit formation and price indexation. Table 5 reports the results for the comparison between the model with learning (and no habits and indexation) and the model with rational expectations, incorporating habits and indexation.

The model with learning fits better than the model with rational expectations. When both models incorporate habits and indexation, the data favor the model with learning (the Bayes factor equals 584 in favor of learning). More important is the case in which I instead compare the model with learning, but no sources of mechanical persistence, with the model with rational expectations, enriched with habit formation and inflation indexation. I therefore re-estimate the model with learning assuming $\eta=0$ and $\gamma=0$. Not having habits and indexation, the MSV solution of the system also changes: agents therefore use the following simpler Perceived Law of Motion as their forecasting rule:

$$
Z_{t}=a_{t}+b_{t} i_{t-1}+c_{t} u_{t}+d_{t} r_{t}^{n}+\varepsilon_{t}
$$

Now the Bayes factor assumes value $2.6764 * 10^{6}$. According to Jeffreys (1961), such a value represents decisive evidence of one model versus the other (a researcher should have prior probability $2.6764 * 10^{6}$ higher for the rational expectations model to overturn the results). The posterior model probabilities favor the specification with learning over rational expectations with weight 1 versus 0 .

A possible criticism of models with learning is that they entail more parameters to be estimated than does the rational expectations alternative, for they require explicit modeling of expectations.

\footnotetext{
${ }^{37}$ See appendix for details.
} 
But under rational expectations researchers need to incorporate a number of additional extensions to make the model fit satisfactorily. Under learning, such extensions might be avoided. The learning model leads to substitution of coefficients regarding frictions with coefficients about agents' beliefs. Modeling the updating of beliefs can be useful to understand particular historical episodes and papers by Orphanides and Williams (2003a,b, 2005), Primiceri (2003), and Sargent, Williams and Zha (2004) are all steps in that direction.

I have shown that learning is favored by the data in the context of a popular model of monetary policy transmission. This finding suggests that learning might similarly be important in more complicated models à la Smets and Wouters (2003), for example, which still need several frictions and exogenous shocks to fit the data. The importance of learning in such a rich model is not demonstrated here, however, and I will verify it in future research. More general forms of habits and indexation may be thought, for example, allowing additional lags to enter the model equations (this is also true for agents' learning rules). All the possible cases can still be tested against learning using the techniques described in this paper. Learning seems supported by the data, however, because it allows to model parameter variation, maintaining parsimony of additional parameters.

\section{Extensions}

In this section, I consider a number of extensions to the baseline model and verify how the results are affected by different assumptions. First, I consider a different approach of introducing learning, described in Preston (2003). Preston introduces learning from the primitives of a DSGE model and shows that under subjective expectations the derived equations will be different from those under rational expectations, for long-horizon expectations about macroeconomic variables also matter (this approach has been labeled Infinite-Horizon learning by Honkapohja, Mitra and Evans 2003, whereas they refer to the alternative approach as Euler Equation learning). ${ }^{38}$ I shall present the model under Infinite-Horizon learning (leaving the full details of the derivation in the appendix) and the implied empirical results.

An immediate possible criticism of the baseline model of the paper concerns the choice of a constant monetary policy rule through the sample. Agents' beliefs might just incorporate the effect of the omitted policy variation in the model. Policy changes over the sample may generate persistence in the system and learning might simply proxy for changing policy. Therefore, I reestimate the model for the post-1982 sample, which many economists would agree have represented

\footnotetext{
${ }^{38}$ For a discussion of the two alternative approaches, see Honkapohja, Mitra and Evans (2003), and Preston (2004c).
} 
a single policy regime, characterized by an active monetary policy rule and low volatility shocks. Then, I explicitly model time variation in policy introducing a time-varying inflation target used by the central bank, as in Smets and Wouters (2003). Other extensions concern the robustness of the results to different priors, different gain coefficients, and different initializations of the learning algorithm.

6.1. Infinite-Horizon Learning. With learning introduced as in Preston (2003), long-horizon expectations also matter. Here, I generalize Preston's framework to include habit formation and indexation. The model economy can be summarized ${ }^{39}$ as follows

$$
\begin{aligned}
\widetilde{x}_{t} & =\widehat{E}_{t} \sum_{T=t}^{\infty} \beta^{T-t}\left[(1-\beta) \widetilde{x}_{T+1}-(1-\eta \beta) \sigma\left(i_{T}-\pi_{T+1}-r_{T}^{n}\right)\right] \\
\widetilde{\pi}_{t} & =\widehat{E}_{t} \sum_{T=t}^{\infty}(\alpha \beta)^{T-t}\left[\xi_{p}\left(\omega x_{T}+[(1-\eta \beta) \sigma]^{-1} \widetilde{x}_{T}\right)+(1-\alpha) \beta \widetilde{\pi}_{T+1}+u_{T}\right] \\
i_{t} & =\rho i_{t-1}+(1-\rho)\left[\chi_{\pi} \pi_{t}+\chi_{x} x_{t}\right]+\varepsilon_{t} \\
r_{t}^{n} & =\phi_{r} r_{t-1}^{n}+\nu_{t}^{r} \\
u_{t} & =\phi_{u} u_{t-1}+\nu_{t}^{u}
\end{aligned}
$$

where $\widetilde{x}_{t}$ and $\widetilde{\pi}_{t}$ have the usual meaning. Notice that the implied dynamics for output gap and inflation are different from those derived under Euler Equation learning (equations (3.1) and (3.2)). In this model, agents need to form forecasts of macroeconomic variables until the indefinite future. Also, as clear from equation (6.1), agents have more to learn about. They also need to learn future interest rates, for example, while these forecasts were not required under Euler Equation learning. As before, agents form forecasts for any horizon $T>t$ as described in (3.11).

The paper provides the first empirical analysis of a model with Infinite-Horizon learning. The results presented in Table 6 provide evidence similar to that from the baseline model. The degree of habit formation is slightly higher $(\eta=0.17)$, but still small. Indexation is also higher $(\gamma=0.2)$, but again much smaller than under rational expectations. In particular, with infinite-horizon learning the required small degree of indexation is paired with an almost nil estimated autocorrelation of the supply shock $\left(\phi_{u}=0.017\right)$. Therefore, learning permits to avoid the assumption of extremely autocorrelated exogenous shocks and large degrees of additional sources of persistence. In this model, I directly estimate $\alpha$, the Calvo parameter indicating the degree of price stickiness. This coefficient is estimated to equal 0.138 , at a value considerably lower than the estimates in the

\footnotetext{
${ }^{39}$ See complete derivation in the appendix.
} 
literature, which often fall in the range 0.8-0.9. ${ }^{40}$ My estimate suggests prices fixed for 1.16 quarters. The estimate is therefore more consistent with the microeconomic evidence on price rigidity (for example, Bils and Klenow 2004 find that firms adjust prices every 1-2 quarters). The intertemporal elasticity of substitution $\sigma$ is now strongly reduced (0.05), while the gain coefficient becomes larger (0.028).

The fit of the model with Infinite-Horizon learning, however, is not as good as the fit for the model with Euler Equation learning. Infinite expectations in fact magnify the forecast errors of the agents, leading to a less satisfactory empirical performance. Nonetheless, the success of the infinite-horizon model in attenuating the estimated autocorrelation of exogenous shocks and, most importantly, the implied degree of price rigidity, reveals that additional research under this approach may be valuable. In current work, I am more deeply comparing estimated models with Euler Equation and Infinite-Horizon learning.

\section{Insert Table 6 about here}

6.2. Single Policy Regime: Post-1982 Sample. For the purposes of this paper, the assumption of a constant monetary policy rule over the post-war sample would be troubling only if the persistence in the economy was actually driven by the omitted evolving policy. I therefore estimate the learning model for the Volcker-Greenspan sample 1982:IV-2004:II (I exclude the 1979-82 non-borrowed reserves targeting interval, which Sims and Zha (2004) find to represent a different regime). Under this regime it is widely agreed that monetary policy has been active and stabilizing (and well approximated by a Taylor rule with smoothing) and also macroeconomic volatility has been considerably lower than in previous decades (researchers refer to this decline in volatility as "The Great Moderation"). I present the results in Table 7.

\section{Insert Table 7 about here}

The results still do not indicate degrees of habit formation and indexation comparable to those estimated under rational expectations $(\eta=0.13, \gamma=0.11)$. This would suggest that learning is not simply capturing the omitted policy variation in the baseline model. Milani (2005) evaluates if the result can be pushed further, by reconsidering the evidence in favor of regime shifts in U.S. monetary policy in the post-war period. Clarida, Galì, and Gertler (2000), in a widely cited paper, find that monetary policy evolved from passive (one that did not respond to inflation with a coefficient above 1) in the pre-1979 period to active in the post-1982 period. They also conclude that monetary policy

\footnotetext{
${ }^{40} \mathrm{~A}$ recent exception is Altig et al. (2004).
} 
was conducive to instability if embedded in a standard New-Keynesian model. In their analysis, they rely on rational expectations. Milani (2005) finds instead that if learning replaces rational expectations, the estimation of the model with learning over the post-war sample provides evidence of a far less drastic time variation in policy. The paper in fact shows that monetary policy has been stabilizing over the whole sample. But in the pre-1979 period, the policymaker and private sector's expectations were misaligned because of a persistent underestimation of the degree of inflation persistence and a persistent overestimation of the slope of the Phillips curve. A similar result is also more consistent with the evidence from a-theoretical VAR models (Sims and Zha 2004, for example) that find weak or no time variation in the monetary policy coefficients over time.

Looking at the estimates, it seems that the gain coefficient has been lower in the post-1982 sample $(\overline{\mathbf{g}}=0.0058$, indicating agents that use roughly 172 quarterly observations to form their expectations).

6.3. Time-Varying Inflation Target. Suppose now that the central bank has adopted, for some exogenous reasons, a time-varying inflation target over the sample. Monetary policy can be expressed by the following rule

$$
i_{t}=\rho i_{t-1}+(1-\rho)\left[\pi_{t}^{*}+\chi_{\pi}\left(\pi_{t}-\pi_{t}^{*}\right)+\chi_{x} x_{t}\right]+\varepsilon_{t}
$$

where the inflation target $\pi_{t}^{*}$ evolves as an $\mathrm{AR}(1)$ process

$$
\pi_{t}^{*}=\phi_{\pi^{*}} \pi_{t-1}^{*}+\nu_{t}^{\pi^{*}}
$$

A similar monetary policy rule with a time-varying target for inflation has been used by Smets and Wouters (2003) and Onatski and Williams (2004). The rest of the model is unchanged and given by expressions (3.1), (3.2), (3.6), and (3.7).

Now the agents' Perceived Law of Motion becomes

$$
Z_{t}=a_{t}+b_{t} Z_{t-1}+c_{t} u_{t}+d_{t} r_{t}^{n}+e_{t} \pi_{t}^{*}+\varepsilon_{t}
$$

in which they also react to the current period inflation target. Table 7 reports the estimates. The assumption of time-varying policy does not overturn the results. Again there is no evidence of indexation in inflation $(\gamma=0.035)$. I also find a positive but low degree of habit formation $(\eta=0.146)$. The estimated gain is also higher and equal to $0.035 .^{41}$

\footnotetext{
${ }^{41}$ Here the target becomes known to the agents when forming expectations (because it appears in the new MSV solution) and therefore their learning can be faster than before.
} 
It is interesting to look at the evolution of the time-varying inflation target over time. Figure 3 reports the federal funds rate (solid line) together with the estimated inflation target (dashed line).

\section{Insert Figure 3 about here}

As expected, the target is low in the 1960s, it jumps and stays high during the 1970s (values around 5-6\%), and it remains low during the Volcker-Greenspan period (3-4\%). More surprising might be the behavior of the target in the last part of the sample, where it is increasing. This may either indicate that the central bank has indeed adopted a higher target or that the target consistent with a desired response of the economy has shifted. A possible explanation might be that concerns about the zero-bound for interest rates in the last part of the sample led the Federal Reserve to behave as if its inflation target was higher (not responding to changes in the economy for fear to hit the zero-bound). The target falls at the beginning of the 1980s during Volcker chairmanship, and remains extremely low during the disinflation. The target even hits zero in this period: real interest rates were in fact raised a lot, despite the deep recession the U.S. economy was experiencing. The behavior of the inflation target series is similar to that found by Kozicki and Tinsley (2003). ${ }^{42}$

6.4. Different Priors. In the baseline case, I have assumed a Gamma prior distribution with mean 0.031 for the crucial parameter $\bar{g}$. But since no previous papers have attempted to estimate the gain from time series data, it is hard to have a tight prior belief. In this section, I therefore employ a more diffuse prior distribution, assuming that the gain follows a Uniform distribution in the interval $[0,0.3]$. The prior mean is now 0.15 , substantially higher than the previous one, and the prior standard deviation is 0.087. Table 7 again reports the results. Even with the more diffuse prior, I obtain $\overline{\mathbf{g}}=0.01835$, very similar to the value estimated in the baseline case. The other estimated coefficients are also absolutely similar.

6.5. Different Learning Speeds for Output and Inflation. So far, I have assumed that economic agents are learning the law of motions of different variables at the same rate. In this section, I relax this assumption: the learning process can occur at different speeds when it refers to output or inflation. Therefore I allow for two gain coefficients in the estimation, which I denote $\overline{\mathbf{g}}^{x}$ for the output gap and $\overline{\mathbf{g}}^{\pi}$ for inflation.

The estimated values reported in table 7 demonstrate the robustness of the results to this extension. The estimated degrees of habits and indexation remain negligible $(\eta=0.103, \gamma=0.03)$. The

\footnotetext{
${ }^{42}$ In their model, they have also assumed a time-varying perceived target by private agents, different from the time-varying target implemented by the central bank.
} 
gain concerning the output gap is estimated equal to 0.0161, the gain concerning inflation instead equals 0.0247. The data are therefore suggestive of faster learning in the dynamics of inflation. The other estimates are again substantially unchanged.

6.6. Estimated Initial Beliefs. I re-estimate the model under a different set of values to initialize the learning algorithm. The initial beliefs are now estimated from pre-sample data (1954:III1959:IV). The implied habit formation and indexation parameters are small $(\eta=0.178, \gamma=0.02)$; the gain coefficient is now larger $(\overline{\mathbf{g}}=0.035)$.

\section{Welfare and Policy Implications}

Understanding the true sources of inertia in the economy is fundamental for policy. Whether the persistence in the economy is driven by structural features or by the dynamics of agents' evolving expectations has non-trivial implications for the optimal monetary policy. If the features that are introduced in the models mainly to improve their empirical performance turn out to be a mistaken representation of the economy, then the welfare analysis based on such microeconomic foundations will be misleading.

7.1. Rational Expectations and Mechanical Sources of Persistence. Suppose expectations are formed rationally and the inertial behavior of economic variables is induced by habit formation in consumption and indexation in price-setting. Woodford (2003) shows that in a DSGE model built on such microfoundations, a second-order Taylor expansion of the consumer utility function implies the following welfare-based loss function to be minimized by the policy maker

$$
E_{t}\left\{\sum_{T=t}^{\infty} \beta^{T-t}\left[\left(\pi_{t}-\gamma \pi_{t-1}\right)^{2}+\lambda_{x}\left(x_{t}-\delta x_{t-1}-\bar{x}^{*}\right)^{2}\right]\right\}
$$

where $\lambda_{x}=\frac{\xi_{p} \eta}{(1-\beta \eta) \sigma \delta \theta}, 0 \leq \delta \leq \eta$ is the smaller root of the quadratic equation $\eta \varphi\left(1+\beta \delta^{2}\right)=$ $\left[\omega+\varphi\left(1+\beta \eta^{2}\right)\right] \delta,{ }^{43}$ and $\bar{x}^{*}>0$ is a function of microeconomic distortions affecting steady-state output, such as the degree of market power and the size of tax distortions in the economy. Therefore, both habit formation and indexation affect the implied loss function, in which now also lagged terms for inflation and output gap appear. ${ }^{44}$ The implied loss function, using the estimated parameters

\footnotetext{
${ }^{43}$ The parameter $\delta$ is an increasing function of $\eta$, holding fixed the other parameters, and a decreasing function of the marginal disutility of supplying output, measured by $\omega$, holding $\eta$ fixed.

${ }^{44}$ When habits are not present, i.e. the case $\eta=0$ and $\delta=0$, it can be shown that $\frac{\delta}{\eta}$ converges to $\frac{\varphi}{\omega+\varphi}$ and therefore $\lambda_{x}=\frac{\xi_{p}\left(\omega+\sigma^{-1}\right)}{\theta}=\frac{\kappa}{\theta}$.
} 
in the previous sections, has weights $\gamma=0.885, \lambda_{x}=0.00028$ (assuming elasticity of substitution among differentiated goods $\theta=7.69$, as in Giannoni and Woodford 2003) and $\delta=0.612$.

An optimizing policymaker will seek to minimize such loss function subject to the sequence of constraints given by the aggregate supply relation under rational expectations. The minimization yields the first-order conditions

$$
\begin{aligned}
\pi_{t}-\gamma \pi_{t-1}+\psi_{t}-\psi_{t-1} & =0 \\
\lambda_{x}\left(x_{t}-\delta x_{t-1}-\bar{x}^{*}\right)-\kappa \psi_{t}+\kappa \delta \psi_{t-1} & =0
\end{aligned}
$$

where $\psi_{t}$ is the associated Lagrange multiplier. The optimal target criterion for commitment under the timeless perspective is therefore given by

$$
\pi_{t}-\gamma \pi_{t-1}=-\frac{\lambda_{x}}{\kappa}\left(x_{t}-x_{t-1}\right)
$$

The optimal target criterion depends on $\gamma$, the estimated degree of indexation, but it is unaffected by $\eta$, the estimated degree of habit persistence. Habit persistence however matters in the choice of the instrument rate to achieve the preferred output and inflation paths (and in the choice of the feasible paths). The optimal instrument rate path is given by

$$
i_{t}=\psi_{\pi} \pi_{t-1}+\psi_{x} x_{t-1}+\psi_{u} u_{t}+r_{t}^{n}
$$

where $\psi_{\pi}, \psi_{x}, \psi_{u}$ are feedback coefficients, the response to $\pi_{t-1}$ in the optimal rule arises from indexation, and the response to $x_{t-1}$ arises from both habits and commitment.

7.2. Learning. On the other hand, if expectations and learning drive the persistence in the economy (assuming no role for habits and indexation) a welfare-based loss function derived in the same way as before would be the more standard

$$
E_{t}\left\{\sum_{T=t}^{\infty} \beta^{T-t}\left[\pi_{t}^{2}+\lambda_{x}\left(x_{t}-x^{*}\right)^{2}\right]\right\}
$$

where $\lambda_{x}=\frac{\kappa}{\theta}$ (which equals 0.035 using the estimated parameters in the learning specification). The constraints under which the policymaker optimizes would be different, now including oneperiod and two-period ahead (or long-horizon) private sector expectations. The optimal target criterion (under commitment) will be given by

$$
\pi_{t}=-\frac{\lambda_{x}}{\kappa}\left(x_{t}-x_{t-1}\right)
$$


Under learning, optimal policy depends on the assumed knowledge of the central bank about agents' expectations formation. The central bank may be assumed to optimize under the assumption that agents have rational expectations, employing the corresponding model to derive optimal policy. As an alternative, the central bank may be assumed to have perfect knowledge about the expectations formation mechanism of the agents, recognizing their learning rules.

Under the assumption of rational expectations, the optimal rule is given by a linear function of the state variables and it does not depend on agents' learning. Preston (2004a,b) shows that if the central bank misperceives the manner in which agents form expectations, the economy will be more prone to instability.

Suppose instead that the central bank correctly understands agents' learning rules. Satisfaction of the optimal target criterion in this case implies, following Evans and Honkapohja (2003a), the optimal reaction function

$$
i_{t}=\frac{1}{\sigma}\left[\widehat{E}_{t} x_{t+1}-\frac{\lambda_{x}}{\lambda_{x}+\kappa^{2}} x_{t-1}+\left(\frac{\beta \kappa}{\lambda_{x}+\kappa^{2}}+\sigma\right) \widehat{E}_{t} \pi_{t+1}+\frac{\kappa}{\lambda_{x}+\kappa^{2}} u_{t}+\sigma r_{t}^{n}\right]
$$

This reaction function implies satisfaction of the optimal target criterion independently from the expectations held by the agents. It is apparent from the targeting rule that the central bank needs to monitor and respond to private sector forecasts of future macroeconomic conditions. It is also clear that learning and rational expectations lead to different optimal rules. The management of expectations becomes a fundamental task for the central bank. Also, learning adds a further argument for transparency. ${ }^{45}$ A transparent central bank facilitates the learning process of the private sector and minimizes the fluctuations due to private expectations becoming uncoupled from the objectives of policy. ${ }^{46}$ Orphanides and Williams (2003a) illustrate the benefits of adopting an inflation target that is known by the private sector.

But what is the cost of a policymaker misperceiving the expectations formation of the agents? Does the optimal monetary policy obtained under the assumption of rational expectations perform reasonably well when agents have instead imperfect knowledge? Here, I try to briefly provide some preliminary evidence. A full analysis of optimal policy under learning deserves further study and will be a priority for future research.

Assume that the true structure of the economy is represented by the model with learning, as described by equations (3.1) and (3.2), focusing for simplicity on the case of no habits and no

\footnotetext{
${ }^{45}$ See Faust and Svensson (2001) for a study of the importance of transparency and credibility in monetary policy.

${ }^{46}$ The role of central bank transparency when the private sector is learning is also discussed in Svensson (2003).
} 
indexation $(\eta=\gamma=0) .{ }^{47}$ The policymaker therefore minimizes the more standard quadratic loss function (7.6). First, I compute the optimal policy taking agents' learning into account (the policymaker correctly understands agents' expectations formation). The optimal policy under learning implies a loss equal to $4.306,{ }^{48}$ as shown in Table 8 .

\section{Insert Table 8 about here}

Suppose now that the policymaker optimizes under the mistaken assumption that agents have fully rational expectations. ${ }^{49}$ If the policymaker implements the optimal policy assuming rational expectations, but the true representation of the economy is instead one with learning, the implied loss will be equal to 7.150. The welfare cost arising from a misspecification of the expectations formation mechanism is substantial.

A recent study by Orphanides and Williams (2004) illustrates similar results. They find that monetary policies that appear optimal under rational expectations perform poorly when knowledge is instead imperfect. ${ }^{50}$ In addition, their work shows that policies that account for learning are not too sensitive to potential misspecifications of the true learning mechanism. Schmitt-Grohe' and Uribe (2004), instead, derive what they call 'simple optimal operational' policy rules in a rich rational expectations model (à la Christiano, Eichenbaum and Evans) with habits and indexation: they find the optimality of a significant degree of inflation volatility. They point out that their result is due to the indexation to past inflation, when the assumption of zero long-run inflation is relaxed. Price indexation in fact limits price dispersion, rendering inflation less costly. This again remarks the important differences arising from alternative modeling assumptions to induce persistence in the macroeconomic variables and shows the potential counterintuitive results that can emerge. It also highlights the potential importance of a comparison between optimal policies found by Schmitt-Grohe' and Uribe (2004) in rich rational expectations models, and optimal policies with learning.

\footnotetext{
${ }^{47}$ In this exercise, I use the previously estimated coefficients for the model equations, and the optimal weights in the loss function are those implied by the estimated coefficients.

${ }^{48}$ Here the loss is calculated as the weighted sum of variances.

49 The model coefficients remain the same: the only difference therefore lies in the assumed expectations formation.

${ }^{50}$ Orphanides and Williams (2004) point out that the poor performance of optimal policy under rational expectations derives from a relatively weaker response to inflation, which creates a vicious circle where inflation expectations and actual inflation reinforce each other. It is also interesting to notice that the optimal response to inflation, in their paper, appears to be an increasing function of the gain (at least in their assumed range).
} 


\section{Conclusions and Future Directions}

A long-standing issue in macroeconomics has been how to endogenously generate persistence in the dynamics of economic variables to match stylized facts about aggregate data. Several extensions in various sides of the economy are typically needed to induce inertia in conventional rational expectations models of the monetary transmission mechanism.

This paper has presented a simple model with learning. Agents do not know the structural parameters of the economy and use econometric models and historical data to infer parameters and form expectations over time. Realistic levels of persistence arise in the model from the updating of agents' beliefs. As a consequence, some extensions that are typically needed in rational expectations models to match the observed inertia, such as habit formation in consumption or indexation to past inflation, become unsupported by the data under learning. Learning can therefore represent a potential single mechanism, which can induce persistence without recurring to several modifications in different sides of the economy. Moreover, learning helps to improve the fit of current monetary DSGE models. The specification with learning fits significantly better than the specification with rational expectations, according to the posterior model probabilities.

On the methodological side, the econometric approach of the paper has allowed joint estimation of the main learning rule coefficient (the constant gain), together with the structural parameters of the economy. Since the results in models with learning may be heavily dependent on the choice of the gain, this procedure avoids potentially important arbitrariness.

If learning is indeed an important characteristic of the structure of the economy, as suggested by the paper's empirical evidence, it will be necessary to derive optimal monetary policy taking agents' learning behavior into account. The cost of misspecifying the level of agents' rationality should be more deeply studied. An ideal optimal policy should be robust to small deviations from fully rational expectations and to misperceptions of agents' learning rules. In the paper, I find that policymakers may incur substantial costs from a misspecification of the private sector expectations formation (if policymakers assume agents have rational expectations, when instead they are learning). Similarly, the interaction between policy and agents' beliefs, as well as among optimal policy, learning speed, and persistence, requires further study. For example, recent papers by Orphanides and Williams (2003b) and Gaspar and Vestin (2004) show that the interaction between monetary policy and agents' learning about the economy may reduce the capacity of policymakers to stabilize the economy, compared with a perfect knowledge environment. Branch, Carlson, Evans, and McGough (2004) also study the interaction between optimal monetary policy 
and the anchoring of inflation expectations to explain the decline in macroeconomic volatility after the 1980s.

I have presented the results in a stylized model of the US economy. In future research, I shall analyze if the results hold in richer models, such as those employed by Christiano, Eichenbaum and Evans (2005), Altig et al. (2004), and Smets and Wouters (2003, 2004, 2005), which also incorporate capital accumulation. The scope of the paper, however, was to propose learning as a potential propagation mechanism in the economy and to start showing its relevance in a simple monetary model, but which still embeds alternative sources of endogenous inertia.

Although not shown in the paper, learning might similarly represent an important propagation mechanism in other frameworks that currently lack endogenous persistence. Learning can be exploited in the context of the New Open Economy Macroeconomics, for example. Also, the empirical importance of evolving expectations and learning may be examined in a Real Business Cycle model, revisiting an old Keynesian idea, to study how shocks to expectations compete with technology shocks (Chari, Kehoe, and McGrattan 2004) and demand shocks (Gali' and Rabanal 2004) as driving forces of business cycles. All of these issues are on the research agenda. 


\section{REFERENCES}

[1] Altig, D., Christiano, L.J., Eichenbaum, M., and J.Linde', (2004). "Firm-Specific Capital, Nominal Rigidities and the Business Cycle", mimeo, Northwestern University.

[2] Amato, J.D., and T.Laubach (2003). "Rule-of-Thumb Behaviour and Monetary Policy", European Economic Review, Volume 47, Issue 5 , pp. 791-831.

[3] — (2004). "Implications of Habit Formation for Optimal Monetary Policy", Journal of Monetary Economics, vol. 51(2), pages 305-325.

[4] Ascari, G., (2004). "Staggered Prices and Trend Inflation: Some Nuisances", Review of Economic Dynamics 7 , 642-667.

[5] BAll, L., (2000). "Near-Rationality and Inflation in Two Monetary Regimes", NBER WP No. 7988, October.

[6] Bils, M., and P. Klenow, (2004). "Some Evidence on the Importance of Sticky Prices", Journal of Political Economy, 112, pages 947-985.

[7] Boivin, J., and M. Giannoni, (2003). "Has Monetary Policy Become More Effective?", NBER Working Paper no. 9459, January.

[8] Branch, W.A., Carlson, J., Evans, G.W., and B. McGough, (2004). "Monetary Policy, Endogenous Inattention, and the Volatility Trade-off", mimeo.

[9] Branch, W.A., and G.W. Evans, (2005). "A Simple Recursive Forecasting Model", Economics Letters, forthcoming.

[10] Bullard, J., and S. Eusepi, (2005). "Did The Great Inflation Occur Despite Policymaker Commitment to a Taylor Rule?", Review of Economic Dynamics, vol. 8(2), pages 324-359.

[11] Bullard, J., and K. Mitra, (2002). "Learning About Monetary Policy Rules", Journal of Monetary Economics, 49, pp. 1105-1129.

[12] Calvo, G., (1983). "Staggered Prices in a Utility-Maximizing Framework", Journal of Monetary Economics, 12(4), pp. 983-998.

[13] Chari, V.V., Kehoe, P. J., and E. McGrattan, (2004). "Business Cycle Accounting", NBER Working Paper 10351, March.

[14] Christiano, L.J., Eichenbaum, M., and C.L. Evans, (2005). "Nominal Rigidities and the Dynamic Effects of a Shock to Monetary Policy", Journal of Political Economy, Vol. 113 (1).

[15] Clarida, R., Gali', J., and M. Gertler, (1999). "The Science of Monetary Policy: a New Keynesian Perspective," Journal of Economic Literature, 37, 1661- 1707.

[16] - (2000). "Monetary Policy Rules and Macroeconomic Stability: Evidence and Some Theory", Quarterly Journal of Economics, vol. CXV, issue 1, pp. 147-180.

[17] Cogley, T., and T.J. Sargent, (2004). "Anticipated Utility and Rational Expectations as Approximations of Bayesian Decisions Making", mimeo, UC Davis and New York University.

[18] - (2005a). "Drifts and Volatilities: Monetary Policies and Outcomes in the Post WWII US", Review of Economic Dynamics, Vol. 8 (2), pages 262-302.

[19] — (2005b). "The Conquest of U.S. Inflation: Learning and Robustness to Model Uncertainty", Review of Economic Dynamics, Vol. 8 (2), pages 528-563.

[20] Collard and Dellas (2004). "The New Keynesian Model with Imperfect Information and Learning", mimeo, GREMAQ and University of Bern.

[21] DeJong, D., Ingram, B., and C. Whiteman, (2000). "A Bayesian Approach to Dynamic Macroeconomics", Journal of Econometrics, 98(2), 203-223.

[22] Dennis, R., (2003). "New Keynesian Optimal-Policy Models: An Empirical Assessment", Federal Reserve Bank of San Francisco Working Paper 03-16.

[23] Dynan, K., (2000). "Habit Formation in Consumer Preferences: Evidence from Panel Data", American Economic Review, vol. 90, pp. 391-406.

[24] Estrella, A., and J. Fuhrer (2002). "Dynamic Inconsistencies: Counterfactual Implications of a Class of Rational-Expectations Models", American Economic Review, vol. 92(4), pp. 1013-1028, September.

[25] Evans, G.W., and S. Honkapohja, (2001). Learning and Expectations in Macroeconomics, Princeton University Press.

[26] - (2003a). "Monetary Policy, Expectations and Commitment", mimeo, University of Oregon and University of Cambridge.

[27] — (2003b). "Adaptive Learning and Monetary Policy Design", Journal of Money, Credit and Banking, vol.35, pp. 1045-1072.

[28] Faust, J., and L.E.O. Svensson, (2001). "Transparency and Credibility: Monetary Policy with Unobservable Goals", International Economic Review 42, pp. 369-397.

[29] Feldstein, M., (1999). "Interest-Rate Rules in an Estimated Sticky Price Model: Comment", Monetary Policy Rules, in J.B. Taylor, ed., University of Chicago Press.

[30] Fernandez-Villaverde, J., and J.F. Rubio-Ramirez, (2004a). "Comparing Dynamic Equilibrium Economies to Data", Journal of Econometrics, 123, pp 153-187.

[31] — (2004b). "Estimating Dynamic Equilibrium Economies: Linear versus Nonlinear Likelihood", forthcoming, Journal of Applied Econometrics.

[32] Fuhrer, J., (2000a). Comment on "Near-Rationality and Inflation in Two Monetary Regimes" by L. Ball. 
[33] — (2000b). "Habit Formation in Consumption and its Implications for Monetary Policy", American Economic Review, vol. 90(3), pp. 367-390, June.

[34] — (2004). Comment on "Empirical and Policy Performance of a Forward-Looking Monetary Model" by A. Onatski and N. Williams.

[35] Gali', J., and M. Gertler, (1999). "Inflation Dynamics: a Structural Econometric Analysis", Journal of Monetary Economics, Volume 44, Issue 2, pp. 195-222.

[36] Gali', J., and P. Rabanal, (2004). "Technology Shocks and Aggregate Fluctuations: How Well Does the RBC Model Fit Postwar U.S. Data?", NBER Macroeconomics Annual, 2004.

[37] Gaspar, V., and D. Vestin, (2004). "Imperfect Knowledge, Learning, and Conservatism", mimeo, January.

[38] Geweke, J.F., (1992). "Evaluating the Accuracy of Sampling-Based Approaches to the Calculation of Posterior Moments", in J.O. Berger, J.M. Bernardo, A.P. Dawid, and A.F.M. Smith (eds.), Proceedings of the Fourth Valencia International Meeting on Bayesian Statistics, pp. 169-194, Oxford University Press.

[39] - (1999). "Using Simulation Methods for Bayesian Econometric Models: Inference, Development and Communication", Econometric Reviews, 18(1), 1-73.

[40] Giannoni, M., and M. Woodford, (2003). "Optimal Inflation Targeting Rules", Ben S. Bernanke and Michael Woodford, eds., Inflation Targeting, Chicago: University of Chicago Press.

[41] Goodfriend, M.S., and R.G. King, (1997). "The New Neoclassical Synthesis and the Role of Monetary Policy", NBER Macroeconomics Annual, 1997, 231-283.

[42] Gordon, D.B., and E. Leeper, (2003). "Are Countercyclical Policies Counterproductive?", mimeo, Indiana University.

[43] Honkapohja, S., Mitra, K., and G. Evans, (2003). "Notes on Agent's Behavioral Rules Under Adaptive Learning and Recent Studies of Monetary Policy", unpublished manuscript.

[44] Ireland, P., (2003). "Irrational Expectations and Econometric Practice", unpublished manuscript.

[45] — (2004). "A Method for Taking the Models to the Data" Journal of Economic Dynamics and Control, vol. 28(6), pages 1205-1226.

[46] Jeffreys, H., (1961). "Theory of Probability", Oxford University Press, Oxford.

[47] Justiniano, A., and B. Preston, (2004). "Small Open Economy DSGE Models: Specification, Estimation and Model Fit", mimeo, IMF and Columbia University.

[48] Kiley, M., (2004). "Is Moderate-To-High Inflation Inherently Unstable?", Federal Reserve Board of Governors, Finance and Economics Discussion Series 2004-43.

[49] Kozicki, S., and P.A. Tinsley, (2003). "Permanent and Transitory Policy Shocks in an Empirical Macro Model with Asymmetric Information", Federal Reserve Bank of Kansas City, WP 03-09.

[50] Kreps, D., (1998). "Anticipated Utility and Dynamic Choice", 1997 Schwartz Lecture, in Frontiers of Research in Economic Theory, Edited by Donald P. Jacobs, Ehud Kalai, and Morton Kamien, Cambridge University Press, Cambridge, England

[51] Laforte, J.P., (2003). "Comparing Monetary Policy Rules in an Estimated General Equilibrium Model of the US Economy", mimeo, Princeton University.

[52] Landon-Lane, J., (2002). "Evaluating Dynamic Stochastic General Equilibrium Models using Likelihood", mimeo, Rutgers University.

[53] Lubik, T., and F. Schorfheide, (2003). "Do Central Banks Respond to Exchange Rates? A Structural Investigation", mimeo, Johns Hopkins University and University of Pennsylvania.

[54] (2004). "Testing for Indeterminacy: an Application to U.S. Monetary Policy", American Economic Review, 94(1), pp. 190-217.

[55] Marcet, A., and Nicolini J.P., (2003). "Recurrent Hyperinflations and Learning", American Economic Review, vol. 93 , no. 5 , pp. 1476-1498.

[56] McCallum, B.T., (1988). "Robustness Properties of a Rule for Monetary Policy", Carnegie Rochester Conference Series on Public Policy, 29, 173- 204.

[57] - (1999). "Role of the Minimal State Variable Criterion in Rational Expectations Models", International Tax and Public Finance, Kluwer Academic Publishers, vol. 6(4), pages 621-39, November.

[58] McCallum, B.T., and E. Nelson, (1999). "An Optimizing IS-LM Specification for Monetary Policy and Business Cycle Analysis", Journal of Money, Credit and Banking, Ohio State University Press, vol. 31(3), pages 296-316, August.

[59] Milani, F., (2004). "Adaptive Learning and Inflation Persistence", mimeo, Princeton University.

[60] - (2005). "Learning, Monetary Policy Rules, and Macroeconomic Stability", mimeo, Princeton University.

[61] Onatski, A., and N. Williams, (2004). "Empirical and Policy Performance of a Forward-Looking Monetary Model", mimeo, Columbia University and Princeton University.

[62] Orphanides, A., and J. Williams, (2003a). "Imperfect Knowledge, Inflation Expectations and Monetary Policy", in Ben Bernanke and Michael Woodford, eds., Inflation Targeting. Chicago: University of Chicago Press.

[63] — (2003b). "The Decline of Activist Stabilization Policy: Natural Rate Misperceptions, Learning, and Expectations", Journal of Economic Dynamics and Control, forthcoming.

[64] - (2004). "Robust Monetary Policy with Imperfect Knowledge", paper presented at the Conference on Monetary Policy and Imperfect Knowledge, Wurzburg, October 14-15.

[65] - (2005). "Inflation Scares and Forecast-Based Monetary Policy", Review of Economic Dynamics, Vol. 8 (2), pages 498-527. 
[66] Oтroк, C., (2001). "On Measuring The Welfare Cost of Business Cycles", Journal of Monetary Economics, Vol 47, pp. 61-92.

[67] Preston, B., (2003). "Learning About Monetary Policy Rules When Long-Horizon Expectations Matter", forthcoming, International Journal of Central Banking.

[68] - (2004a). "Adaptive Learning and the Use of Forecasts in Monetary Policy", forthcoming, Journal of Monetary Economics.

[69] (2004b). "Adaptive Learning, Forecast-Based Instrument Rules and Monetary Policy", mimeo, Columbia University.

[70] - (2004c). "Adaptive Learning in Infinite Horizon Decisions Problems", mimeo, Columbia University.

[71] Primiceri, G., (2003). "Why Inflation Rose and Fell: Policymakers' Beliefs and Postwar Stabilization Policy", mimeo, Princeton University.

[72] Rabanal, P., and J.F. Rubio-Ramirez, (2003). "Comparing New Keynesian Models of the Business Cycle : A Bayesian approach", Journal of Monetary Economics, forthcoming.

[73] Raftery, A.E., and S.M. Lewis, (1995). "The Number of Iterations, Convergence Diagnostics, and Generic Metropolis algorithms", Practical Markov Chain Monte Carlo, W.R. Gilks, D.J. Spiegelhalter, and S. Richardson, eds., Chapman and Hall, London.

[74] Rotemberg, J., and M. Woodford, (1997). "An Optimization-Based Econometric Model for the Evaluation of Monetary Policy", NBER Macroeconomics Annual 12, 297-346.

[75] — (1999). "Interest-Rate Rules in an Estimated Sticky-Price Model", in Monetary Policy Rules, J.B. Taylor, ed., University of Chicago Press.

[76] Sargent, T.J., (1993). Bounded Rationality in Macroeconomics. Oxford University Press.

[77] — (1999). The Conquest of American Inflation. Princeton University Press.

[78] Sargent, T.J., Williams, N., and T. Zha, (2004). "Shocks and Government Beliefs: The Rise and Fall of American Inflation", NBER Working Paper No. 10764.

[79] Schmitt-Grohe', S., and M. Uribe, (2004). "Optimal Operational Monetary Policy in the ChristianoEichenbaum-Evans Model of the U.S. Business Cycle", mimeo, Duke University.

[80] Schorfheide, F., (2005). "Learning and Monetary Policy Shifts", Review of Economic Dynamics, Vol. 8(2), pages 392-419.

[81] Sims, C.A., (2001). "Stability and Instability in US Monetary Policy Behavior", mimeo, Princeton University.

[82] — (2002). "Solving Linear Rational Expectations Models", Computational Economics, 20, 1-20.

[83] Sims, C.A., and T. ZhA, (2004). "Were There Regime Switches in US Monetary Policy?", American Economic Review, forthcoming.

[84] Smets, F., and R. Wouters, (2003). "Monetary Policy in an Estimated Stochastic Dynamic General Equilibrium Model of the Euro Area", Journal of the European Economic Association, v. 1, iss. 5, pp. 1123-75.

[85] — (2004). "Forecasting with a Bayesian DSGE Model: An Application to the Euro Area", Journal of Common Market Studies, 42 (4), 841-867.

[86] — (2005). "Comparing Shocks and Frictions in US and Euro Business Cycles: A Bayesian DSGE Approach", Journal of Applied Econometrics, Vol. 20, No. 2, 2005, pp. 161-183.

[87] Svensson, L.E.O., (2003). "Monetary Policy and Learning", Federal Reserve Bank of Atlanta Economic Review, Third Quarter, 11-16.

[88] Williams, N., (2003). "Adaptive Learning and Business Cycles", mimeo, Princeton University.

[89] Woodford, M., (1998). "Doing Without Money: Controlling Inflation in a Post-Monetary World", Review of Economic Dynamics 1, 173-219, 1998.

[90] - (2003). Interest and Prices: Foundations of a Theory of Monetary Policy, Princeton University Press.

[91] Yu, B., and P. MYkland (1994). "Looking at Markov Samplers through CUMSUM path plots: a simple diagnostic idea", Technical Report 413, Dept. of Statistics, University of California at Berkeley. 


\section{Appendix A. The Model under Infinite-Horizon Learning}

In this appendix, I will derive the aggregate dynamics of the economy introducing learning directly from the primitive assumptions, as in Preston (2003). This section generalizes Preston (2003) incorporating also habit formation in consumption and inflation indexation in price-setting. In the model, agents know: 1) their own preferences; 2) the constraints they face; 3) how to solve their optimization problems. They do not have any knowledge of other agents' preferences though. Therefore, they are not able to infer the aggregate probability laws of the variables of interest, as they would instead be under rational expectations.

A.1. Households' Optimal Consumption Decisions. Each household $i$ still maximizes

$$
\widehat{E}_{t}^{i}\left\{\sum_{T=t}^{\infty} \beta^{T-t}\left[U\left(C_{T}^{i}-\eta C_{T-1}^{i} ; \zeta_{T}\right)-\int_{0}^{1} v\left(h_{T}^{i}(j) ; \zeta_{T}\right) d j\right]\right\}
$$

where $\widehat{E}_{t}^{i}$ indicates subjective expectations for household $i$. For simplicity, I assume homogeneous beliefs across agents (although this is not known to agents, who do not have any information about other agents' beliefs). As standard in the adaptive learning literature, the subjective expectations of individual agents obey the law of iterated expectations, $\widehat{E}_{t}^{i} \widehat{E}_{t+s}^{i} z=\widehat{E}_{t}^{i} z$ for any variable $z$.

I follow Preston (2003a) in assuming incomplete asset markets. ${ }^{51}$ Agents can use a single oneperiod riskless asset to transfer wealth intertemporally. The flow budget constraint is given by:

$$
M_{t}^{i}+B_{t}^{i} \leq\left(1+i_{t-1}^{m}\right) M_{t-1}^{i}+\left(1+i_{t-1}\right) B_{t-1}^{i}+P_{t} Y_{t}^{i}-T_{t}-P_{t} C_{t}^{i}
$$

where $M_{t}^{i}$ denotes end-of-period money holdings, $B_{t}^{i}$ end-of-period riskless bond holdings, $i_{t}^{m}$ and $i_{t}$ denote nominal interest rates on money and bonds, and $T_{t}$ are lump sum taxes and transfers. $Y_{t}^{i}$ is household's real income in period $t$, given by $\int_{0}^{1}\left[w_{t}(j) h_{t}^{i}(j)+\Pi_{t}(j)\right] d j$, where $w_{t}(j)$ represents the wage received by the household for labor supplied in the production of good $j$ and $\Pi_{t}(j)$ the share of profits received from the sale of each firm's good $j$ (households own an equal share of all the firms).

Substituting the first-order conditions as in(2.4) into (2.5), and taking a log-linear approximation of the implied Euler equation, I obtain an expression like (2.6), only indexed by $i$ now.

The intertemporal budget constraint (IBC) is of the form:

$$
\widehat{E}_{t}^{i} \sum_{T=t}^{\infty} \beta^{T-t} \widehat{C}_{T}^{i}=\omega_{t}^{i}+\widehat{E}_{t}^{i} \sum_{T=t}^{\infty} \beta^{T-t} \widehat{Y}_{T}^{i}
$$

\footnotetext{
${ }^{51}$ This assumption limits the extent of information revelation from prices.
} 
where $\omega_{t}^{i} \equiv \frac{W_{t}^{i}}{P_{t} \bar{Y}}$ is the share of nominal wealth $\left(W_{t}^{i} \equiv\left(1+i_{t-1}\right) B_{t-1}^{i}\right)$ as a fraction of nominal steady-state income.

Solving (2.6) backwards, taking expectations and substituting into the modified IBC $^{52}$ yields

$$
\begin{aligned}
\widehat{C}_{t}^{i}= & (1-\beta) \omega_{t}^{i}+\frac{\eta}{1+\beta \eta} \widehat{C}_{t-1}^{i}+\frac{\beta \eta}{1+\beta \eta} \widehat{E}_{t}^{i} \widehat{C}_{t+1}^{i}+\widehat{E}_{t}^{i} \sum_{T=t}^{\infty} \beta^{T-t}\left[(1-\beta) \widehat{Y}_{T}^{i}-\frac{\eta(1-\beta)}{1+\beta \eta} \widehat{C}_{T-1}^{i}+\right. \\
& \left.-\frac{\beta \eta(1-\beta)}{1+\beta \eta} \widehat{C}_{T+1}^{i}-\frac{\beta(1-\eta \beta)}{1+\beta \eta} \sigma\left(\widehat{i}_{T}-\widehat{\pi}_{T+1}\right)+\frac{\beta}{1+\beta \eta}\left(g_{T}-g_{T+1}\right)\right]
\end{aligned}
$$

Integrating over $i$, I obtain:

$$
\begin{aligned}
C_{t}= & \frac{\eta}{1+\beta \eta} C_{t-1}+\frac{\beta \eta}{1+\beta \eta} \widehat{E}_{t} C_{t+1}+\widehat{E}_{t} \sum_{T=t}^{\infty} \beta^{T-t}\left[(1-\beta) Y_{T}-\frac{\eta(1-\beta)}{1+\beta \eta} C_{T-1}+\right. \\
& \left.-\frac{\beta \eta(1-\beta)}{1+\beta \eta} C_{T+1}-\frac{\beta(1-\eta \beta)}{1+\beta \eta} \sigma\left(i_{T}-\pi_{T+1}\right)+\frac{\beta}{1+\beta \eta}\left(g_{T}-g_{T+1}\right)\right]
\end{aligned}
$$

where I have used $\int_{i} \omega_{t}^{i} d i=0$ from bond's market clearing, $C_{t}^{i}=\int_{i} C_{t}^{i} d i, Y_{t}^{i}=\int_{i} Y_{t}^{i} d i$, and $\widehat{E}_{t}[\cdot] \equiv \int_{i} \widehat{E}_{t}^{i}[\cdot] d i$, the latter denoting average private-sector expectations. Using the equilibrium relationship $C_{t}=Y_{t}$, and re-expressing in terms of the output gap $x_{t} \equiv Y_{t}-Y_{t}^{n}$ yields

$$
\widetilde{x}_{t}=\widehat{E}_{t} \sum_{T=t}^{\infty} \beta^{T-t}\left[(1-\beta) \widetilde{x}_{T+1}-(1-\eta \beta) \sigma\left(i_{T}-\pi_{T+1}-r_{T}^{n}\right)\right]
$$

where

$$
\widetilde{x}_{t} \equiv\left(x_{t}-\eta x_{t-1}\right)-\beta \eta \widehat{E}_{t}\left(x_{t+1}-\eta x_{t}\right)
$$

and $Y_{t}^{n}$ is the natural rate of output (the equilibrium level of output under flexible prices) and $r_{T}^{n} \equiv[(1-\eta \beta) \sigma]^{-1}\left[\left(Y_{t+1}^{n}-g_{t+1}\right)-\left(Y_{t}^{n}-g_{t}\right)\right]$ is the flexible-price equilibrium real interest rate (the real interest rate in an equilibrium where $x_{t}=0$ at all times). Notice that now current output gap depends on lagged and expected one-period ahead output gap, plus on long-horizon forecasts of future gaps, real interest rates and exogenous disturbances until the infinite future.

A.2. Firms' Problem. Each firm $i$ maximizes the expected present discounted value of future profits

$$
\widehat{E}_{t}^{i}\left\{\sum_{T=t}^{\infty} \alpha^{T-t} Q_{t, T}\left[\Pi_{T}^{i}\left(p_{t}^{*}(i)\left(\frac{P_{T-1}}{P_{t-1}}\right)^{\gamma}\right)\right]\right\}
$$

The first-order conditions for the problem are

$$
\widehat{E}_{t}^{i}\left\{\begin{array}{c}
\sum_{T=t}^{\infty}(\alpha \beta)^{T-t} \lambda_{T} Y_{T} P_{T}^{\theta}\left(\frac{P_{T-1}}{P_{t-1}}\right)^{\gamma(1-\theta)} \cdot \\
{\left[p_{t}^{*}(i)-\mu P_{T} s\left(Y_{T}\left(\frac{\widehat{p}_{t}^{*}(i)}{P_{T}}\right)^{-\theta}\left(\frac{P_{T-1}}{P_{t-1}}\right)^{-\gamma \theta}, Y_{T} ; \widetilde{\zeta}_{T}\right)\right]}
\end{array}\right\}=0
$$

\footnotetext{
${ }^{52}$ Found by substituting $\widehat{C}_{t}^{i}=\widetilde{C}_{t}^{i}+\eta \widehat{C}_{t-1}^{i}+\beta \eta \widehat{E}_{t}^{i}\left[\widehat{C}_{t+1}^{i}-\eta \widehat{C}_{t}^{i}\right]$ into the IBC.
} 
where $\mu=\theta /(\theta-1)>1, \widetilde{\zeta}_{t}$ is a vector of exogenous real disturbances incorporating both preference shocks $\zeta_{t}$ and technology shocks $A_{t}$, and where $s(\cdot)$ is firm $i$ 's real marginal cost function expressed as

$$
s\left(y_{t}(i), Y_{T} ; \widetilde{\zeta}_{T}\right) \equiv\left(\frac{v_{h}\left(f^{-1}\left(y_{t}(i) / A_{t}\right) ; \zeta_{t}\right)}{\lambda_{t} A_{t}}\right)\left(\frac{1}{f^{\prime}\left(f^{-1}\left(y_{t}(i) / A_{t}\right)\right)}\right)
$$

Log-linearization of the first-order condition again yields

$$
\widehat{p}_{t}^{*}(i)=\widehat{E}_{t}^{i} \sum_{T=t}^{\infty}(\alpha \beta)^{T-t}\left[\frac{1-\alpha \beta}{1+\omega \theta}\left(\omega \widehat{Y}_{T}-\widehat{\lambda}_{T}+\frac{v_{y \zeta}}{v_{y}} \zeta_{T}\right)+\alpha \beta\left(\widehat{\pi}_{T+1}-\gamma \widehat{\pi}_{T}\right)\right]
$$

where $\widehat{p}_{t}^{*} \equiv \log \left(p_{t}^{*} / P_{t}\right)$ and $\omega \equiv v_{y y} \bar{Y} / v_{y}$ is the elasticity of the marginal disutility of producing output with respect to an increase in output.

Integrating over $i$

$$
\widehat{p}_{t}^{*}=\widehat{E}_{t} \sum_{T=t}^{\infty}(\alpha \beta)^{T-t}\left[\frac{1-\alpha \beta}{1+\omega \theta}\left(\omega \widehat{Y}_{T}-\widehat{\lambda}_{T}+\frac{v_{y \zeta}}{v_{y}} \zeta_{T}\right)+\alpha \beta\left(\widehat{\pi}_{T+1}-\gamma \widehat{\pi}_{T}\right)\right]
$$

which from a log-linear approximation of the aggregate price index (2.11) permits to derive

$$
\begin{aligned}
\tilde{\pi}_{t}= & \xi_{p}\left(\omega x_{t}+[(1-\eta \beta) \sigma]^{-1} \widetilde{x}_{t}\right)+\widehat{E}_{t} \sum_{T=t}^{\infty}(\alpha \beta)^{T-t} \\
& {\left[\alpha \beta \xi_{p}\left(\omega x_{T+1}+[(1-\eta \beta) \sigma]^{-1} \widetilde{x}_{T+1}\right)+(1-\alpha) \beta \widetilde{\pi}_{T+1}+u_{T}\right] }
\end{aligned}
$$

where

$$
\begin{gathered}
\tilde{\pi}_{t} \equiv \widehat{\pi}_{t}-\gamma \widehat{\pi}_{t-1} \\
\widetilde{x}_{t} \equiv\left(x_{t}-\eta x_{t-1}\right)-\beta \eta \widehat{E}\left(x_{t+1}-\eta x_{t}\right) \\
\xi_{p}=\frac{(1-\alpha)(1-\alpha \beta)}{\alpha(1+\omega \theta)}
\end{gathered}
$$

Equivalently, expression (A.13) can be re-expressed (see Woodford (2003)) as

$$
\widetilde{\pi}_{t}=\kappa \bar{x}_{t}+\widehat{E}_{t} \sum_{T=t}^{\infty}(\alpha \beta)^{T-t}\left[\kappa \alpha \beta \bar{x}_{T+1}+(1-\alpha) \beta \widetilde{\pi}_{T+1}+u_{T}\right]
$$

where $\kappa \equiv \frac{\xi_{p} \eta}{(1-\eta \beta) \sigma \delta}>0, \bar{x}_{t}=\left(x_{t}-\delta x_{t-1}\right)-\beta \delta \widehat{E}_{t}\left(x_{t+1}-\delta x_{t}\right), 0 \leq \delta \leq \eta$ and $\delta$ is the smaller root of the quadratic equation $\eta \varphi\left(1+\beta \delta^{2}\right)=\left[\omega+\varphi\left(1+\beta \eta^{2}\right)\right] \delta$. Notice that current inflation therefore depends on lagged inflation, current, lagged and one-period ahead output gaps, and on the long-horizon forecasts of future output gaps, inflation rates and supply shocks. 


\section{Appendix B. Econometric Procedure}

B.1. Kalman Filter. To generate draws from the posterior distribution of $\theta$ using the Metropolis algorithm, I need to evaluate the likelihood function $p\left(Y^{T} \mid \theta\right)$ at each iteration. Having expressed the model as a linear Gaussian system, I can easily compute the likelihood recursively with the Kalman Filter.

I run the Kalman filter recursion with standard steps to compute first and second moments of the following conditional distributions:

(1) Start from initial values:

$$
p\left(\xi_{t} \mid Y^{t}, \theta\right)
$$

(2) Prediction:

$$
\begin{aligned}
p\left(\xi_{t+1} \mid Y^{t}, \theta\right) & =\int p\left(\xi_{t+1} \mid \xi_{t}, \theta\right) p\left(\xi_{t} \mid Y^{t}, \theta\right) d \xi_{t} \\
p\left(Y_{t+1} \mid Y^{t}, \theta\right) & =\int p\left(Y_{t+1} \mid \xi_{t+1}, Y^{t}, \theta\right) p\left(\xi_{t+1} \mid Y^{t}, \theta\right) d \xi_{t+1}
\end{aligned}
$$

(3) Updating:

$$
p\left(\xi_{t+1} \mid Y^{t+1}, \theta\right)=\frac{p\left(Y_{t+1} \mid \xi_{t+1}, Y^{t}, \theta\right) p\left(\xi_{t+1} \mid Y^{t}, \theta\right)}{p\left(Y_{t+1} \mid Y^{t}, \theta\right)}
$$

(4) Evaluate likelihood function:

$$
p\left(Y^{T} \mid \theta\right)=\prod_{t=1}^{T} p\left(Y_{t} \mid Y^{t-1}, \theta\right)
$$

B.2. Metropolis-Hastings Algorithm. To generate draws from the posterior distribution $p\left(\theta \mid Y^{T}\right)$, I use the Metropolis algorithm. The procedure works as follows.

1. Start from an arbitrary value for the parameter vector $\theta_{0}$. Set $j=1$.

2. Evaluate $p\left(Y^{T} \mid \theta_{0}\right) p\left(\theta_{0}\right)$

3. Generate $\theta_{j}^{*}=\theta_{j-1}+\varepsilon$, where $\theta_{j}^{*}$ is the proposal draw and $\varepsilon \sim N\left(0, c \Sigma_{\varepsilon}\right)$. $c$ is a scale factor that is usually adjusted to keep the acceptance ratio of the $\mathrm{MH}$ algorithm at an optimal rate $(25 \%-40 \%$, see Geweke (1999)).

4. Generate $u$ from Uniform $[0,1]$

5. Set $\begin{cases}\theta_{j}=\theta_{j}^{*} & \text { if } u \leq \alpha\left(\theta_{j-1}, \theta_{j}^{*}\right)=\min \left\{\frac{p\left(Y^{T} \mid \theta_{j}^{*}\right) p\left(\theta_{j}^{*}\right)}{p\left(Y^{T} \mid \theta_{j-1}\right) p\left(\theta_{j-1}\right)}, 1\right\} \\ \theta_{j}=\theta_{j-1} & \text { if } u>\alpha\left(\theta_{j-1}, \theta_{j}^{*}\right)\end{cases}$

6. Repeat for $j+1$ from 2 . until $j=D$ ( $D=$ total number of draws). 
B.3. Convergence. To assess convergence of the MCMC (Markov Chain Monte Carlo) simulation, I performed various checks. First, simple initial checks consist of starting the chain from different initial conditions and comparing the results, or looking at the trace plots of the draws. Then, more formally, I have implemented a number of convergence tests as the ones proposed by Geweke (1992), and Raftery and Lewis (1995). ${ }^{53}$ Geweke's test consists of comparing the partial means $\widehat{\mu}_{1}=\frac{1}{D_{1}} \sum_{j=1}^{D_{1}} g\left(\theta_{j}\right)$ and $\widehat{\mu}_{2}=\frac{1}{D_{2}} \sum_{j=D_{1}+1}^{D_{2}} g\left(\theta_{j}\right)$, obtained from the first $D_{1}$ and last $D_{2}$ simulation draws. I can test the null hypothesis of equal means between the two samples of draws, knowing that for $D \rightarrow \infty$, the quantity $\left(\widehat{\mu}_{1}-\widehat{\mu}_{2}\right) /\left(\frac{\widehat{S}_{g}^{1}(0)}{D_{1}}+\frac{\widehat{S}_{g}^{2}(0)}{D_{2}}\right)^{1 / 2} \Longrightarrow N(0,1)$. I also look at the plots derived from a test proposed by Yu and Mykland (1994), based on the partial sums of the draws. ${ }^{54}$

B.4. Model Comparison. I follow Geweke (1999)'s modified harmonic mean approximation to compute the marginal likelihood. Here I briefly describe the procedure. Let $\widehat{\theta}_{D}=\frac{1}{D} \sum_{d=1}^{D} \theta_{d}$ and $\widehat{\Sigma}_{D}=\frac{1}{D} \sum_{d=1}^{D}\left(\theta_{d}-\widehat{\theta}\right)\left(\theta_{d}-\widehat{\theta}\right)^{\prime}$ be the estimates of $E\left(\theta \mid Y, \mathcal{M}_{i}\right)$ and $\operatorname{var}\left(\theta \mid Y, \mathcal{M}_{i}\right)$ obtained from the output of the posterior simulator. Then, for a given $p \in(0,1)$, define the support of $f(\theta)$ :

$$
\widehat{\Theta}_{D}=\left\{\theta:\left(\theta_{d}-\widehat{\theta}\right) \widehat{\Sigma}_{D}^{-1}\left(\theta_{d}-\widehat{\theta}\right)^{\prime} \leq \chi_{1-p}^{2}(k)\right\}
$$

where $\chi_{1-p}^{2}(k)$ is the $(1-p)$ th percentile of the Chi-squared distribution with degrees of freedom equal to the number of parameters $k$. Geweke (1999) recommends using the following Multivariate Normal density truncated to the region $\widehat{\Theta}_{D}$ as $f(\theta)$ :

$$
f(\theta)=\frac{1}{p(2 \pi)^{k / 2}}\left|\widehat{\Sigma}_{D}\right|^{-1 / 2} \exp \left[-\frac{1}{2}\left(\theta_{d}-\widehat{\theta}\right) \widehat{\Sigma}_{D}^{-1}\left(\theta_{d}-\widehat{\theta}\right)^{\prime}\right] 1\left(\theta \in \widehat{\Theta}_{D}\right)
$$

where $\mathbf{1}(\cdot)$ is an indicator function.

\footnotetext{
${ }^{53}$ Raftery and Lewis (1995)'s diagnostics suggests a minimum number of draws by computing the draws' autocorrelation.

${ }^{54}$ They propose the statistics $C S_{t}=\left(\frac{1}{t} \sum_{d=1}^{t} \theta^{d}-\mu_{\theta}\right) / \sigma_{\theta}$, where $\mu_{\theta}$ and $\sigma_{\theta}$ are the empirical mean and standard deviations of the $D$ draws of the Markov Chain. The plot of $C S_{t}$ converges to 0 as we increase $t$.
} 


\begin{tabular}{cclcccc}
\hline \hline Description & Parameters & Range & Prior Distr. & Prior Mean & Prior Std. & $95 \%$ Prior Prob. Int. \\
\hline \hline Habit Formation & $\eta$ & {$[0,1]$} & Uniform & .5 & .289 & {$[0.025,0.975]$} \\
Discount rate & $\beta$ & {$[0,1]$} & Beta & .99 & .01 & {$[0.973,0.999]$} \\
IES & $\sigma$ & $\mathbb{R}^{+}$ & Gamma & .125 & .09 & {$[0.015,0.35]$} \\
Infl. Indexation & $\gamma$ & {$[0,1]$} & Uniform & .5 & .289 & {$[0.025,0.975]$} \\
Function price stick. & $\xi_{p}$ & $\mathbb{R}$ & Gamma & .015 & .011 & {$[0.0019,0.04]$} \\
Elast. mc to inc. & $\omega$ & $\mathbb{R}$ & Normal & .8975 & .4 & {$[0.114,1.68]$} \\
Int-rate smooth. & $\rho$ & {$[0,0.97]$} & Uniform & .485 & .28 & {$[0.024,0.946]$} \\
Feedback Infl. & $\chi_{\pi}$ & $\mathbb{R}^{2}$ & Normal & 1.5 & .25 & {$[1.01,1.99]$} \\
Feedback Gap & $\chi_{x}$ & $\mathbb{R}^{2}$ & Normal & .5 & .25 & {$[0.01,0.99]$} \\
Autoregr. Dem shock & $\phi_{r}$ & {$[0,0.97]$} & Uniform & .485 & .28 & {$[0.024,0.946]$} \\
Autoregr. Sup shock & $\phi_{u}$ & {$[0,0.97]$} & Uniform & .485 & .28 & {$[0.024,0.946]$} \\
MP shock & $\sigma_{\varepsilon}$ & $\mathbb{R}^{+}$ & InvGamma & 1 & .5 & {$[0.34,2.81]$} \\
Demand shock & $\sigma_{r}$ & $\mathbb{R}^{+}$ & InvGamma & 1 & .5 & {$[0.34,2.81]$} \\
Supply shock & $\sigma_{u}$ & $\mathbb{R}^{+}$ & InvGamma & 1 & .5 & {$[0.34,2.81]$} \\
Gain Coeff. & $\overline{\mathrm{g}}$ & $\mathbb{R}^{+}$ & Gamma & .031 & .022 & {$[0.0038,0.087]$} \\
\hline \hline
\end{tabular}

Table 1 - Prior distributions for model with learning.

Notes: The same priors are used for the model with rational expectations, excluding the prior for the gain coefficient $\overline{\mathbf{g}}$, not needed. 


\begin{tabular}{cccc}
\hline \hline Description & Parameters & Posterior Mean & $95 \%$ Post. Prob. Interval \\
\hline \hline Habits & $\eta$ & 0.117 & {$[0.006,0.289]$} \\
Discount & $\beta$ & 0.99 & {$[0.974,0.998]$} \\
IES & $\sigma$ & 0.748 & {$[0.587,0.996]$} \\
Indexation & $\gamma$ & 0.032 & {$[0,0.11]$} \\
Fcn. price stick. & $\xi_{p}$ & 0.016 & {$[0.002,0.04]$} \\
Elast. mc & $\omega$ & 0.865 & {$[0.03,1.61]$} \\
Int-rate smooth. & $\rho$ & 0.914 & {$[0.875,0.947]$} \\
Feedback Infl. & $\chi_{\pi}$ & 1.484 & {$[1.08,1.90]$} \\
Feedback Gap & $\chi_{x}$ & 0.801 & {$[0.433,1.18]$} \\
Autoregr. Dem shock & $\phi_{r}$ & 0.845 & {$[0.776,0.908]$} \\
Autoregr. Sup shock & $\phi_{u}$ & 0.854 & {$[0.778,0.93]$} \\
MP shock & $\sigma_{\varepsilon}$ & 0.86 & {$[0.777,0.953]$} \\
Demand shock & $\sigma_{r}$ & 1.67 & {$[1.47,1.91]$} \\
Supply shock & $\sigma_{u}$ & 1.15 & {$[0.0133,0.0231]$} \\
Gain Coeff. & $\overline{\mathrm{g}}$ & 0.0183 & $1.31]$ \\
\hline \hline
\end{tabular}

Table 2 - Posterior estimates: model with learning. 


\begin{tabular}{ccccc}
\hline \hline \multirow{2}{*}{ Description } & Parameters & Giannoni-Woodford '03 & \multicolumn{2}{c}{ Bayesian Estimation } \\
\cline { 2 - 5 } Habits & $\eta$ & Estimate & Mean Estimate & $95 \%$ Post. Prob. Int. \\
Discount & $\beta$ & 1 & 0.911 & {$[0.717,0.998]$} \\
IES & $\varphi$ & 0.99 (fixed) & 0.9897 & {$[0.971,0.999]$} \\
Indexation & $\gamma$ & 0.6643 & 3.813 & {$[2.285,6.02]$} \\
Fcn. price stick. & $\xi_{p}$ & 1 & 0.885 & {$[0.812,0.957]$} \\
Elast. mc & $\omega$ & 0.0015 & 0.001 & {$[0.0001,0.002]$} \\
Int-rate smooth. & $\rho$ & 0.8975 & 0.837 & {$[0.01,1.63]$} \\
Feedback Infl. & $\chi_{\pi}$ & - & 0.89 & {$[0.849,0.93]$} \\
Feedback Gap & $\chi_{x}$ & - & 1.433 & {$[1.06,1.81]$} \\
Autoregr. Dem shock & $\phi_{r}$ & - & 0.792 & {$[0.425,1.165]$} \\
Autoregr. Sup shock & $\phi_{u}$ & - & 0.87 & {$[0.8,0.93]$} \\
MP shock & $\sigma_{\varepsilon}$ & - & 0.02 & {$[0.0005,0.07]$} \\
Demand shock & $\sigma_{r}$ & - & 0.933 & {$[0.84,1.04]$} \\
Supply shock & $\sigma_{u}$ & - & 1.067 & {$[0.89,1.22]$} \\
\hline \hline
\end{tabular}

Table 3 - Rational Expectations Estimates and 95\% posterior probability interval.

Note: $0.0187 \%$ of the draws fell in the indeterminacy region and were discarded. 


\begin{tabular}{ccc}
\hline \hline & Learning & Rational Expectations \\
\hline \hline Log Marginal Likelihood & -759.08 & -765.45 \\
& $(1.326)$ & $1.316)$ \\
Posterior odds & 584.06 & 1 \\
Posterior probabilities & 0.99829 & 0.0017092 \\
\hline \hline
\end{tabular}

Table 4 - Model Comparison: Learning (with frictions) vs. Rational Expectations (with frictions).

\begin{tabular}{ccc}
\hline \hline & Learning & Rational Expectations \\
\hline \hline Log Marginal Likelihood & $\begin{array}{c}750.65 \\
(1.375)\end{array}$ & $\begin{array}{c}765.45 \\
(1.316)\end{array}$ \\
Posterior odds & $2.6764 * 10^{6}$ & 1 \\
Posterior probabilities & 1 & $3.7363 * 10^{-7}$ \\
\hline \hline
\end{tabular}

Table 5 - Model Comparison: Learning (no frictions) vs. Rational Expectations (with frictions).

Note: log marginal likelihoods are computed using Geweke's Modified Harmonic Mean approximation. 


\begin{tabular}{|c|c|c|}
\hline Parameters & Mean estimate & 95\% Post. Prob. Interval \\
\hline$\eta$ & 0.171 & {$[0.04,0.32]$} \\
\hline$\beta$ & 0.989 & {$[0.97,0.999]$} \\
\hline$\alpha$ & 0.138 & {$[0.02,0.36]$} \\
\hline$\sigma$ & 0.051 & {$[0.02,0.10]$} \\
\hline$\gamma$ & 0.204 & {$[0,0.78]$} \\
\hline$\xi_{p}$ & 0.0015 & - \\
\hline$\omega$ & 0.8975 & - \\
\hline$\rho$ & 0.894 & {$[0.85,0.93]$} \\
\hline$\chi_{\pi}$ & 1.508 & {$[1.14,1.84]$} \\
\hline$\chi_{x}$ & 0.797 & {$[0.41,1.25]$} \\
\hline$\phi_{r}$ & 0.902 & {$[0.82,0.96]$} \\
\hline$\phi_{u}$ & 0.017 & {$[0,0.06]$} \\
\hline$\sigma_{\varepsilon}$ & 0.934 & {$[0.84,1.04]$} \\
\hline$\sigma_{r}$ & 0.822 & {$[0.74,0.91]$} \\
\hline$\sigma_{u}$ & 1.382 & {$[1.12,2.04]$} \\
\hline$\overline{\mathbf{g}}$ & 0.0283 & {$[0.009,0.048]$} \\
\hline
\end{tabular}

Table 6 - Infinite-Horizon Learning: posterior estimates and 95\% posterior probability intervals. 


\begin{tabular}{|c|c|c|c|c|c|c|c|c|c|}
\hline \multirow[b]{2}{*}{ Param. } & \multicolumn{2}{|c|}{ Time-Varying Inflation Target } & \multicolumn{2}{|c|}{ Post-1982 Sample } & \multicolumn{2}{|c|}{ Diff. prior for $\bar{g}$} & \multicolumn{2}{|c|}{ Different gains } & \multirow{2}{*}{$\begin{array}{r}\mathrm{H} \\
\mathrm{Me}\end{array}$} \\
\hline & Mean Est. & $95 \%$ P.I. & Mean & $95 \%$ P.I. & Mean & $95 \%$ P.I. & Mean & 95\% P.I. & \\
\hline$\eta$ & 0.146 & {$[0.01,0.36]$} & 0.13 & {$[0.01,0.29]$} & 0.126 & {$[0.006,0.31]$} & 0.106 & {$[0,0.25]$} & \\
\hline$\beta$ & 0.991 & {$[0.97,0.99]$} & 0.99 & {$[0.97,0.999]$} & 0.99 & {$[0.97,0.999]$} & 0.991 & {$[0.98,0.999]$} & \\
\hline$\sigma$ & 0.44 & {$[0.18,0.73]$} & 1.15 & {$[0.87,1.58]$} & 0.764 & {$[0.58,1.03]$} & 0.767 & {$[0.60,0.98]$} & \\
\hline$\gamma$ & 0.035 & {$[0,0.14]$} & 0.11 & {$[0,0.42]$} & 0.032 & {$[0,0.11]$} & 0.03 & {$[0,0.1]$} & \\
\hline$\xi_{p}$ & 0.0015 & - & 0.0015 & - & 0.0015 & - & 0.0015 & - & 0.0 \\
\hline$\omega$ & 0.8975 & - & 0.82 & {$[0,1.5]$} & 0.892 & {$[0.08,1.63]$} & 0.8975 & - & $0 . \varepsilon$ \\
\hline$\rho$ & 0.917 & {$[0.87,0.96]$} & 0.92 & {$[0.88,0.96]$} & 0.914 & {$[0.88,0.95]$} & 0.913 & {$[0.88,0.94]$} & \\
\hline$\chi_{\pi}$ & 1.47 & {$[1.09,1.78]$} & 1.60 & {$[1.11,2.05]$} & 1.486 & {$[1.09,1.91]$} & 1.46 & {$[1.05,1.87]$} & \\
\hline$\chi_{x}$ & 0.65 & {$[0.4,1]$} & 0.50 & {$[0.13,0.89]$} & 0.784 & {$[0.38,1.18]$} & 0.786 & {$[0.43,1.15]$} & 0. \\
\hline$\phi_{r}$ & 0.838 & {$[0.74,0.93]$} & 0.92 & {$[0.87,0.96]$} & 0.84 & {$[0.77,0.91]$} & 0.84 & {$[0.78,0.90]$} & 0.5 \\
\hline$\phi_{u}$ & 0.831 & {$[0.77,0.90]$} & 0.55 & {$[0.28,0.74]$} & 0.85 & {$[0.78,0.93]$} & 0.85 & {$[0.78,0.93]$} & 0 . \\
\hline$\phi_{\pi^{*}}$ & 0.91 & {$[0.82,0.98]$} & - & - & - & - & - & - & \\
\hline$\overline{\mathrm{g}}$ & 0.0353 & {$[0.022,0.047]$} & 0.0058 & {$[0.0005,0.018]$} & 0.01835 & {$[0.013,0.023]$} & - & - & 0.0 \\
\hline$\overline{\mathbf{g}}^{x}$ & - & - & - & - & - & - & 0.0161 & {$[0.009,0.023]$} & \\
\hline$\overline{\mathbf{g}}^{\pi}$ & - & - & - & - & - & - & 0.0247 & {$[0.004,0.04]$} & \\
\hline
\end{tabular}

Table 7 - Posterior estimates and 95\% posterior probability intervals (EE Learning).

Note: the parameters that are not estimated are fixed at the values in Giannoni and Woodford (2003). 


\begin{tabular}{cc}
\hline \hline & Welfare Loss (learning is 'true' model) \\
\hline Optimal Policy assuming Learning & 4.306 \\
Optimal Policy assuming RE & 7.150 \\
\hline \hline
\end{tabular}

Table $8 \overline{\text { - Welfare losses implied by optimal monetary policies assuming learning and }}$ rational expectations when learning is true model. 

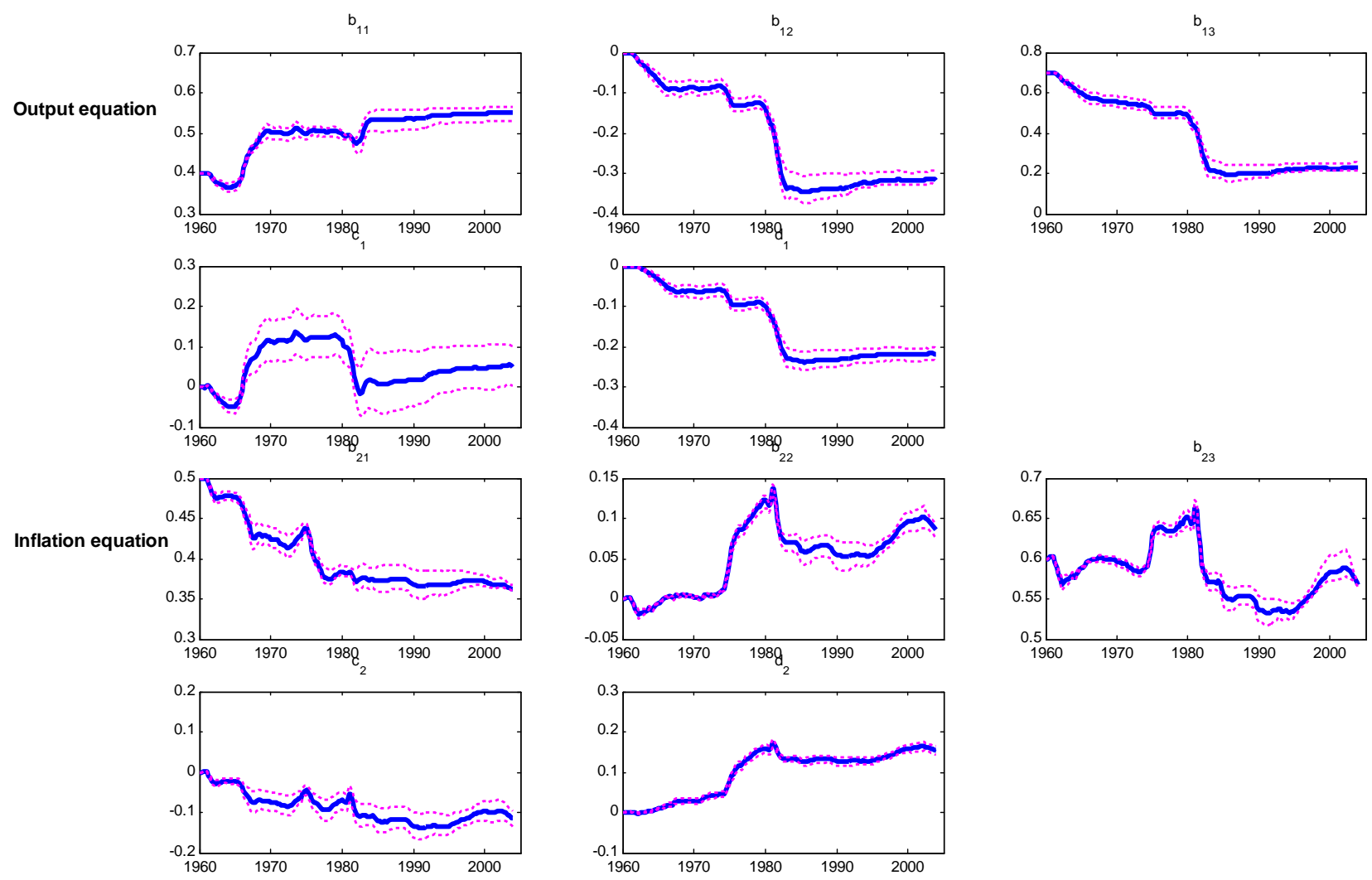

Figure 1 - Evolution of agents' beliefs (1960:I-2004:II).

Agents' learning rule is:

$$
\left[\begin{array}{c}
x_{t} \\
\pi_{t} \\
i_{t}
\end{array}\right]=\left[\begin{array}{ccc}
b_{11, t} & b_{12, t} & b_{13, t} \\
b_{21, t} & b_{22, t} & b_{23, t} \\
0 & 0 & 0
\end{array}\right]\left[\begin{array}{c}
x_{t-1} \\
\pi_{t-1} \\
i_{t-1}
\end{array}\right]+\left[\begin{array}{c}
c_{1, t} \\
c_{2, t} \\
0
\end{array}\right] u_{t}+\left[\begin{array}{c}
d_{1, t} \\
d_{2, t} \\
0
\end{array}\right] r_{t}^{n}+\varepsilon_{t} .
$$




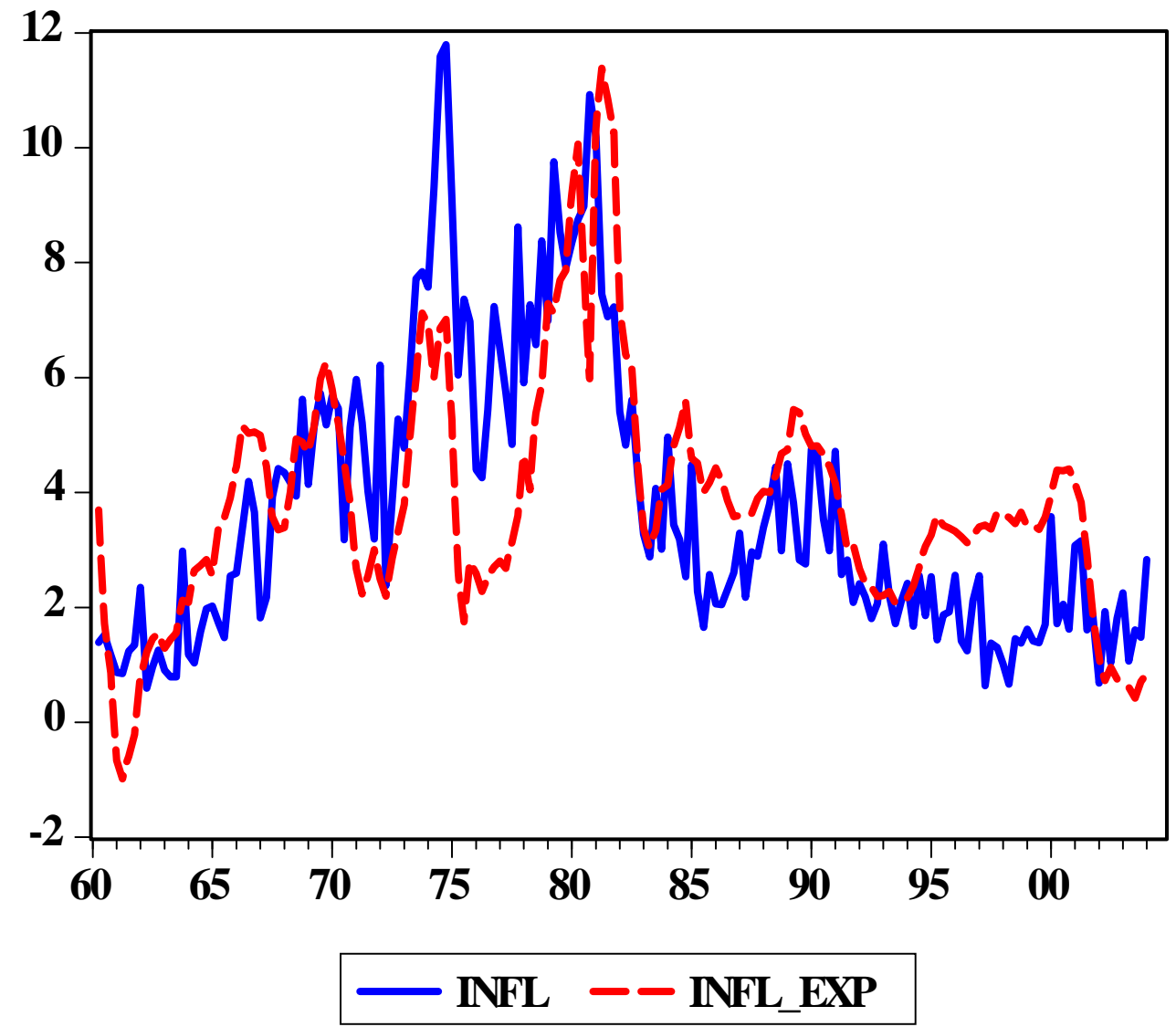

Figure 2 - Actual (solid) and expected (dashed) inflation over the sample. 


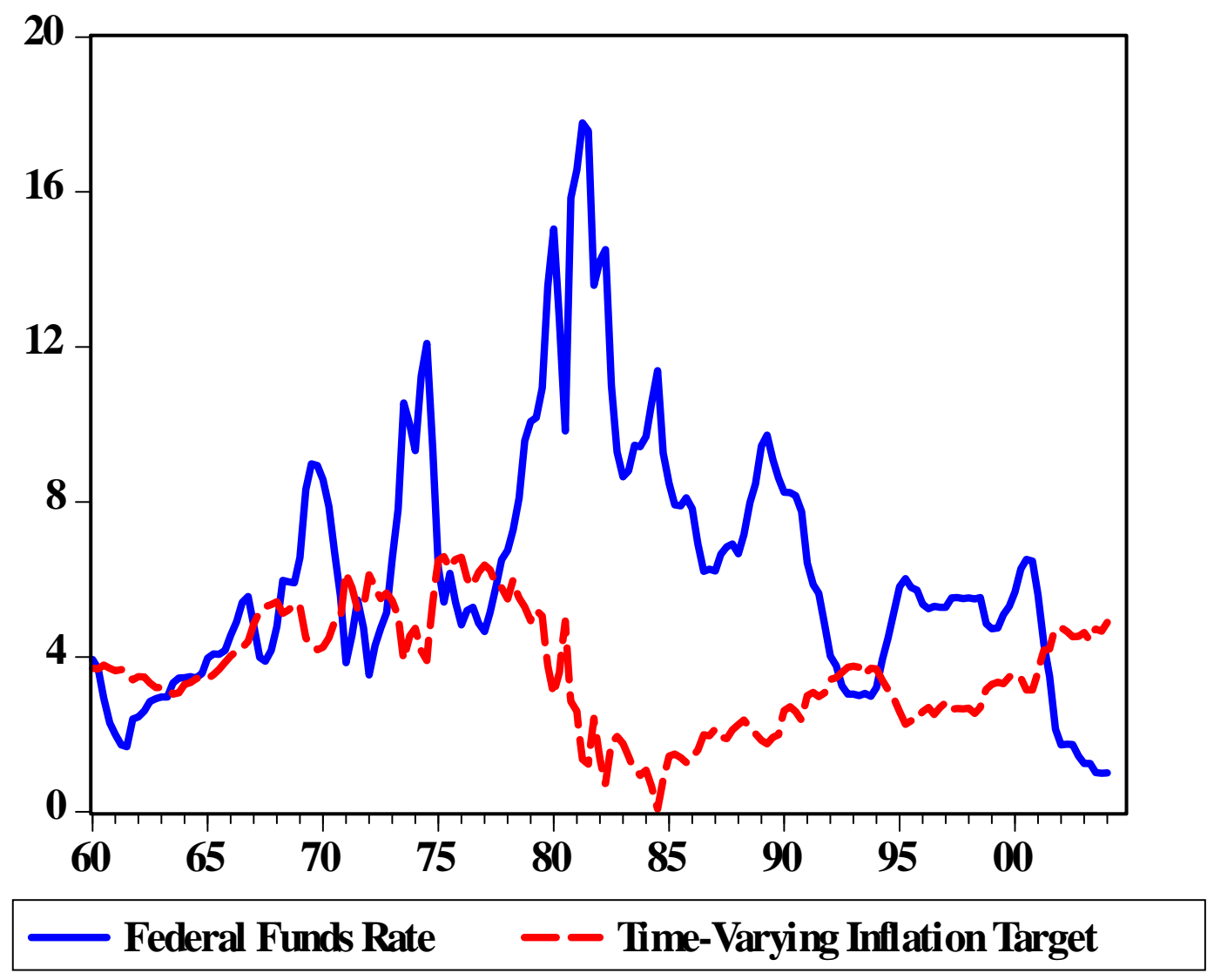

Figure 3 - Federal Funds rate (solid) and time-varying inflation target (dashed). 

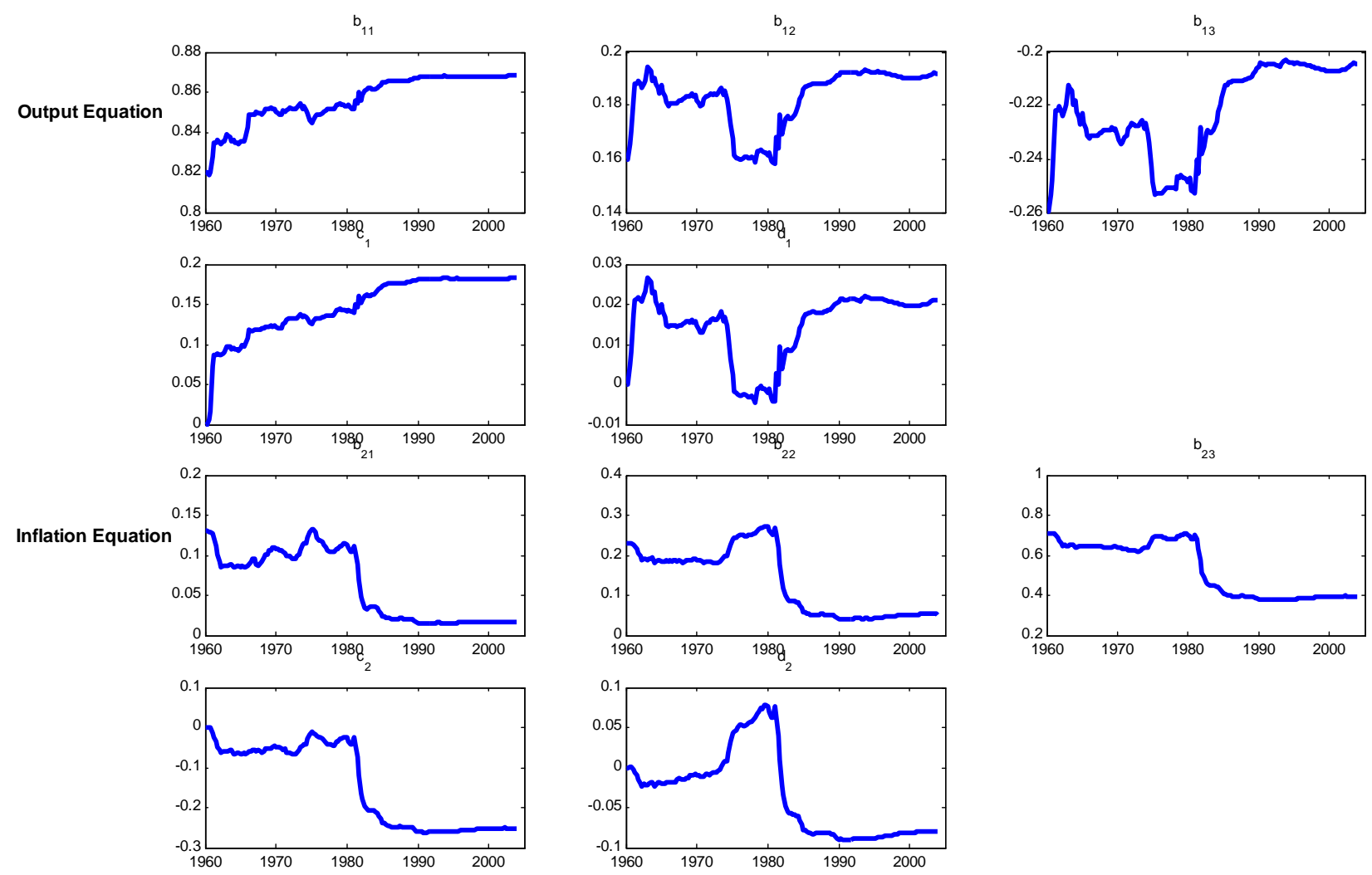

Figure 4 - Evolution of agents' beliefs with estimated initial conditions (1960:I-2004:II).

Agents' learning rule is:

$$
\left[\begin{array}{c}
x_{t} \\
\pi_{t} \\
i_{t}
\end{array}\right]=\left[\begin{array}{ccc}
b_{11, t} & b_{12, t} & b_{13, t} \\
b_{21, t} & b_{22, t} & b_{23, t} \\
0 & 0 & 0
\end{array}\right]\left[\begin{array}{c}
x_{t-1} \\
\pi_{t-1} \\
i_{t-1}
\end{array}\right]+\left[\begin{array}{c}
c_{1, t} \\
c_{2, t} \\
0
\end{array}\right] u_{t}+\left[\begin{array}{c}
d_{1, t} \\
d_{2, t} \\
0
\end{array}\right] r_{t}^{n}+\varepsilon_{t}
$$

Princeton University, Department of Economics, Fisher Hall, Princeton, NJ 08544-1021 or Department of Economics, 3151 Social Science Plaza, University of California, Irvine, CA 92697-5100.

E-mail address: fmilani@uci.edu

URL: http://www.socsci.uci.edu/ fmilani 